\title{
Soluble pre-fibrillar tau and $\beta$-amyloid species emerge in early human Alzheimer's disease and track disease progression and cognitive decline
}

\author{
David J. Koss ${ }^{1} \cdot$ Glynn Jones $^{1} \cdot$ Anna Cranston $^{1} \cdot$ Heidi Gardner $^{1}$. \\ Nicholas M. Kanaan ${ }^{2} \cdot$ Bettina Platt $^{1}$
}

Received: 27 June 2016 / Revised: 7 October 2016 / Accepted: 8 October 2016 / Published online: 21 October 2016

(C) The Author(s) 2016. This article is published with open access at Springerlink.com

\begin{abstract}
Post-mortem investigations of human Alzheimer's disease $(\mathrm{AD})$ have largely failed to provide unequivocal evidence in support of the original amyloid cascade hypothesis, which postulated deposition of $\beta$-amyloid (A $\beta$ ) aggregates to be the cause of a demented state as well as inductive to tau neurofibrillary tangles (NFTs). Conflicting evidence suggests, however, that $\mathrm{A} \beta$ plaques and NFTs, albeit to a lesser extent, are present in a substantial subset of non-demented individuals. Hence, a range of soluble tau and $A \beta$ species has more recently been implicated as the disease-relevant toxic entities. Despite the incorporation of soluble proteins into a revised amyloid cascade hypothesis, a detailed characterization of these species in the context of human $\mathrm{AD}$ onset, progression and cognitive decline has been lacking. Here, lateral temporal lobe samples (Brodmann area 21) of 46 human cases were profiled via tau and $\mathrm{A} \beta$ Western blot and native state dot blot protocols. Elevations in phospho-tau (antibodies: CP13, AT8 and PHF-1), pathological tau conformations (MC-1) and oligomeric tau (TOC1) agreed with medical diagnosis (non-AD cf. AD) and Braak stage classification (low, intermediate and high),
\end{abstract}

Electronic supplementary material The online version of this article (doi:10.1007/s00401-016-1632-3) contains supplementary material, which is available to authorized users.

\footnotetext{
David J. Koss

d.koss@abdn.ac.uk

Bettina Platt

b.platt@abdn.ac.uk

1 School of Medical Sciences, University of Aberdeen, Foresterhill, Aberdeen AB25 2ZD, UK

2 Department of Translational Sciences and Molecular Medicine, College of Human Medicine, Michigan State University, Grand Rapids, MI 49503, USA
}

alongside elevations in soluble $\mathrm{A} \beta$ species (MOAB-2 and pyro-glu $A \beta$ ) and a decline in levels of the amyloid precursor protein. Strong correlations were observed between individual Braak stages and multiple cognitive measures with all tau markers as well as total soluble $A \beta$. In contrast to previous reports, SDS-stable A $\beta$ oligomers (*56) were not found to be reliable for all classifications and appeared likely to be a technical artefact. Critically, the robust predictive value of total soluble $A \beta$ was dependent on native state quantification. Elevations in tau and $\mathrm{A} \beta$ within soluble fractions (Braak stage 2-3 cf. 0) were evident earlier than previously established in fibril-focused disease progression scales. Together, these data provide strong evidence that soluble forms of tau and $\mathrm{A} \beta$ co-localise early in $\mathrm{AD}$ and are closely linked to disease progression and cognitive decline.

Keywords Alzheimer's disease · Amyloid · Tau · Cognitive decline $\cdot$ Dementia $\cdot$ Pathology

\section{Introduction}

The original 'amyloid hypothesis' postulated that aggregated $\beta$-amyloid $(\mathrm{A} \beta)$ drives pathological mechanisms, results in the hyperphosphorylation of the microtubuleassociated protein tau, and causes neurodegeneration and cognitive decline [29]. Accordingly, much of the early work focused on the deposition of $A \beta$ as senile plaques (SPs) and their relationship to the emergence of tau pathology. This work was supported by genetic mutations identified in familial cases of $\mathrm{AD}$ (fAD), and has been greatly influential for both experimental research and therapeutic endeavours. Mutations in the amyloid precursor protein (APP) and the presenilin (PSEN) genes clearly demonstrated that dysfunctions in APP processing are causative of dementia in 
these cases. Yet, the contribution of specific cleavage products and protein aggregates to $\mathrm{AD}$ onset and progression as well as cognitive decline remains highly debated.

A prominent criticism of the amyloid hypothesis has been the lacking association of total plaque load with cognitive status, which is in contrast to the more robust and graded correlation of tau pathology to neuronal loss and symptomatic presentation. Indeed, the highly reproducible regional progression of tau containing neurofibrillary tangles (NFTs) and neuropil threads (NTs) provides the basis for neuropathological severity grading (Braak staging) [15]. Braak staging remains the most accepted post-mortem method of classifying AD progression, although amyloid pathology in the form of SPs and neuritic plaques must also be present to confer a true diagnosis of AD. Overall, NFTs are generally accepted as better indicators of mental impairment, clinical AD symptoms and neurodegeneration over plaque load [26, 53]. Both NFTs and NTs first emerge almost exclusively within the entorhinal cortex (EC) and hippocampal formation (transentorhinal stage, Braak stage 1-2), this pathology alone is associated with little or no cognitive impairment. Only when surrounding cortical and subcortical structures of the limbic system are affected (limbic stage, Braak stage 3-4) do individuals become symptomatic, and definitive symptoms develop fully only once this neuropathology engulfs the neocortex (neocortical stage, Braak stage 5-6).

For the conclusive neuropathological diagnosis of $\mathrm{AD}$, an evaluation of $\mathrm{A} \beta$ depositions via complementary neurohistopathological schemes, such as the five SP-based Thal $(\mathrm{A} \beta$ ) phases and CERAD (Consortium to Establish a Registry for Alzheimer's Disease) staging must be made [12]. However, when considered independently, plaque deposition is less systematic cf. tau pathology and fails to correlate sufficiently with cognitive impairment [71]. Relative to NFTs, SP deposition follows a different spatial progression and is first observed within the neocortex [70]. Plaque numbers become more widespread reaching the EC and hippocampus long after the emergence of NFTs and NTs, with tau and amyloid pathologies only overlapping in advanced stages [73]. Such a spatial divide between the two pathological hallmarks makes it difficult to reconcile the proposed mechanistic and causative link between $A \beta$ and tau, and cannot easily be incorporated into a common pathological scheme.

Despite this scenario, extensive research has focused on targeting amyloid-related pathologies for diagnostic purposes, e.g. based on PET amyloid imaging [78]. More recently, tau-based imaging markers have emerged with promising initial results [16]. Equally, biomarker research in cerebrospinal fluid (CSF) is on the hunt for multifactorial biomarkers, though assays with high specificity and sensitivity remain elusive. For example, a recent multicentre study reported an age-independent occurrence rate of $\sim 22 \%$ of healthy controls $(n=1233)$ in which CSF A $\beta$ levels were low enough to be classified as pathological, yet were negative for neurodegeneration and cognitively intact [76].

Beyond aspects related to disease diagnosis, neither $A \beta$ plaques nor tau NFTs are likely the principle causative factor, as both of these forms of pathology are detected with considerable frequency in a subset of the non-demented population, referred to as non-demented high pathology controls (HPCs) [57]. Moreover, neurons can likely survive with NFT inclusions for several decades [56] and a separation of NFT formation and cognitive decline has been demonstrated in animal models [68]. Recent adaptations of the amyloid cascade hypothesis detail critical interactions with tau pathology, mechanisms of early synaptic loss and highlight central roles of soluble pre-fibril $\mathrm{A} \beta$ and tau species [55].

This shift away from insoluble pathology to potentially earlier emerging soluble $A \beta$ and tau species required advanced biochemical techniques to establish an understanding for the progression of pre-fibrillar pathology. Significantly, a staging of $A \beta$ pathology in line with disease progression has been proposed based on the abundance of low molecular weight $\mathrm{A} \beta$ species in cellular fractions, resolved by SDS-PAGE, and the degree to which these species demonstrate biochemical modifications [67]. The proposed stages correlate with established neuropathological grading scales, such as Braak and CERAD scores, to some degree, suggesting the potential for a stereotypical evolution of molecular pathology. However, associations with cognitive readouts and specific Braak stages were not included in this study. Therefore, a detailed evaluation of potentially pathology relevant soluble tau and $A \beta$ species and their respective association with cognitive decline and disease progression within human cases identified as early and late-stage AD is still lacking.

Here, lateral temporal lobe tissue lysates (Brodmann area 21) from human $A D$ cases and non- $A D$ controls were quantified for phosphorylated, conformationally altered and oligomeric tau species alongside amyloidogenic changes in APP metabolism and levels of total, monomeric, oligomeric and pyro-glutamate (pyro-glu) modified $A \beta$ species. Markers were assessed relative to several classifications, i.e. based on clinical diagnosis, grouped Braak stages $(\mathrm{Br}$ 0-2 cf. 3-4 cf. 5-6) as well as individual Braak stage, and correlated with each other as well as with cognitive decline. Our data demonstrate the earlier coincidence of soluble tau and $\mathrm{A} \beta$ and support the potential pathological role of both proteins early in the disease process of $\mathrm{AD}$. 


\section{Methods}

\section{Tissue samples}

Human temporal cortex samples ( $n=46$, middle temporal gyrus, Brodmann area 21) and corresponding metadata were supplied by MRC London Neurodegenerative Diseases Brain Bank, The Thomas Willis Oxford Brain Collection, The Manchester Brain Bank, The Newcastle Brain Tissue Resource, and The South West Dementia Brain Bank (see Table 1). All samples were received as $500 \mathrm{mg}$ frozen blocks and were stored at $-80{ }^{\circ} \mathrm{C}$ prior to use. Cases were de-identified but information was provided regarding age at death, post-mortem interval (PMI), cortical $\mathrm{pH}$ (where available), neuropathological assessment scores for Braak staging as well as CERAD neuritic plaque scores (where available) and cognitive scores for Mini Mental State Exam (MMSE) as well as global, memory and sum of box (SOB) scores established by the clinical dementia rating system (CDR). For full information regarding individual cases and neuropathological observations see Supplementary Table S1.

To serve as positive and negative immunoblot controls, murine forebrain samples from several transgenic strains were used (12-month old wild-type mice (C57/BL6) and 12-month-old bigenic fAD mice, as previously described [39]). Brain lysates from 12-month-old $\mathrm{BACE} 1^{-1-}$ mice were a generous gift from Prof Michael Ashford (see [54]). Mice were housed and sacrificed in accordance with UK Home Office regulations, University European Directive on the Protection of Animals used for Scientific Purposes (2010/63/EU) and the Animal (Scientific Procedures) Act 1986.

\section{Immunoblot quantification of AD markers}

Quantification of $\mathrm{A} \beta$ and tau markers was based as far as possible on near-native state preparations to limit the degree of sample manipulation required. Therefore, most markers were assessed by dot blots, with the exception of Western blots used for 6E10 and BACE1 antibodies to ascertain detection of single and relevant protein species. The oligomeric tau antibody TOC1 was also validated in Western blots to confirm detection of the previously reported oligomeric species, before samples were fully characterised via dot blots.

\section{Brain lysate preparation}

$100 \mathrm{mg}$ of frozen cortical tissue was homogenised in $\sim 1: 10$ (w/v) Igepal (Sigma, Dorset, UK) based lysis buffer (in mM: 20 HEPES, $150 \mathrm{NaCl}, 0.1$ EDTA, $1 \%$ Igepal:

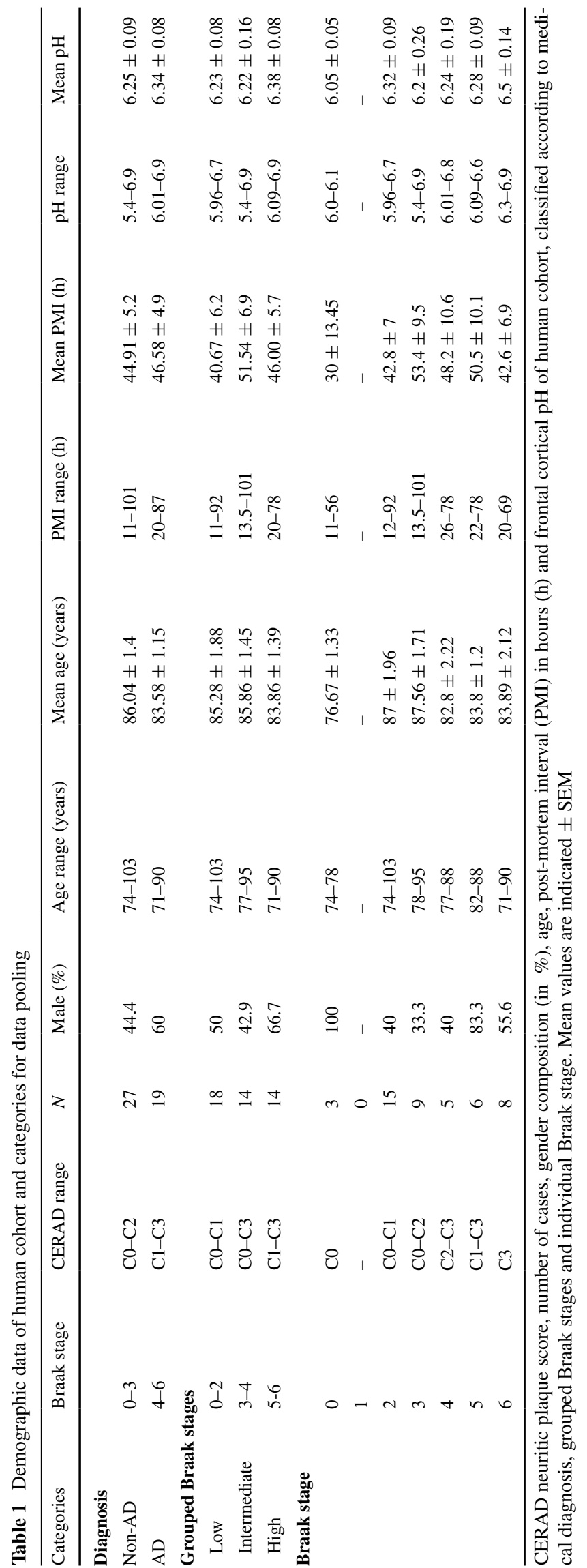


$\mathrm{pH}=7.6$ ). All buffers were supplemented with complete protease inhibitors (Roche) and PhosStop tablets (Roche). The use of the non-ionic, non-denaturing Igepal, which is chemically indistinguishable from the widely used 'Nonidet P-40', ensured adequate lysis of plasma, endoplasmic and Golgi but not nuclear membranes, and prevented aggressive solubilisation of large aggregates [33]. Following manual homogenisation, samples were spun $(13,000 \mathrm{~g}$, $4{ }^{\circ} \mathrm{C}, 20 \mathrm{~min}$ ), supernatants separated from pellets, aliquoted and stored at $-80{ }^{\circ} \mathrm{C}$. For the determination of aggregated non-soluble protein pathology, Igepal derived pellets were re-suspended in excess Igepal buffer $(1 \mathrm{ml})$ homogenised via repeated aspiration with a $1 \mathrm{ml}$ pipette tip, briefly vortexed and spun $\left(13,000 \mathrm{~g}, 4{ }^{\circ} \mathrm{C}, 20 \mathrm{~min}\right)$. Following removal of the supernatants, the process was repeated. Resulting pellets were subsequently re-suspended in $1: 1(\mathrm{w} / \mathrm{v}) 70 \%$ formic acid, incubated overnight at $4{ }^{\circ} \mathrm{C}$ with continuous agitation before a final spin $(18,000 \mathrm{~g}$, $4{ }^{\circ} \mathrm{C}, 20 \mathrm{~min}$ ) to yield the collected supernatant, which was stored at $-80^{\circ} \mathrm{C}$ until use.

\section{SDS-PAGE electrophoresis and protein transfer}

Soluble lysates were adjusted for protein concentration (3 $\mu \mathrm{g} / \mu \mathrm{l})$ as per bicinchoninic acid colorimetric protein assay (BCA, Sigma). For standard denaturing SDS-PAGE electrophoresis, samples were mixed with lithium dodecyl sulphate (LDS, Nupage, Thermo Fisher Scientific, Paisley, UK) and dithiothreitol (15 mM DTT, Sigma) before being boiled for $10 \mathrm{~min}$ at $70{ }^{\circ} \mathrm{C}$. For the identification of oligomeric tau species, samples were treated as above, except without DTT or boiling prior to gel loading. Insoluble samples were first mixed with 4 volumes of neutralising buffer ( $2 \mathrm{M}$ Tris $+2 \mathrm{M} \mathrm{NaH}_{2} \mathrm{PO}_{4}$ ) before the addition of LDS and DTT.

Samples $(30 \mu \mathrm{g} / \mathrm{lane}$ for soluble and $10 \mu \mathrm{l} / \mathrm{lane}$ for neutralised insoluble samples) were separated on 4-12\% Bis-Tris gels (Nupage, Thermo Fisher) under variable conditions dependent on protein target. For $\mathrm{A} \beta$ detection, proteins were separated for $35 \mathrm{~min}$ at $200 \mathrm{~V}$ constant voltage in MES buffer, transferred to $0.2 \mu \mathrm{m}$ nitrocellulose membranes via IBlot (Nupage, Thermo-Fisher), and boiled for 3 min in $0.01 \mathrm{M}$ Dulbecco's $\mathrm{Ca}^{2+}$ and $\mathrm{Mg}^{2+}$ free phosphatase buffered saline (VWR International, Leicestershire, UK). For tau blots, electrophoresis was conducted for $45 \mathrm{~min}$ at $200 \mathrm{~V}$ in MOPS buffer and transferred to $0.45 \mu \mathrm{m}$ nitrocellulose membranes via wet transfer conditions $(1 \mathrm{~h}$, $25 \mathrm{~V}$ constant).

\section{Solubility and protein extractions}

The specific extraction of non-fibrillar proteins from human tissue post-mortem was confirmed in a series of comparative Western blots (Supplementary Figure 1). Total tau, visualised by the HT-7 antibody, demonstrated the selective isolation of tau within well-defined protein bands following Igepal lysis. In contrast, subsequent treatments of the remaining insoluble pellet with $70 \%$ formic acid presented a smear of HT-7 immunoreactivity. This was only evident in $\mathrm{AD}$ cases and is indicative of highly post-translationally modified and aggregated tau species as found in paired helical filaments and NFTs. Similarly, limited solubilisation of amyloid species was observed via Igepal lysis, when compared to that isolated via formic acid from the pellet (see Supplementary Figure 1).

\section{Native state immunoblots}

To ensure the preservation of potentially heat- and conformation-dependent epitopes, dot blots were conducted for a number of $A \beta$ and tau pathological markers. Igepal soluble lysates were adjusted to $2 \mu \mathrm{g} / \mu \mathrm{l}$ with distilled $\mathrm{H}_{2} \mathrm{O}$ (concentration determined with BCA assay, as above) and directly dotted onto $0.2 \mu \mathrm{M}$ nitrocellulose membranes $(5 \mu \mathrm{l} / \mathrm{sam}$ ples, $10 \mu \mathrm{g} / \mathrm{dot}$ ), which were allowed to dry prior to further processing. In a subset of experiments, designed to determine the heat-sensitivity of specific epitopes, lysates were heated $\left(70{ }^{\circ} \mathrm{C}\right.$ for $10 \mathrm{~min}$ ) prior to being dotted.

\section{Blocking and antibody detection}

All immunoblots were washed in $0.05 \%$ Tween 20 (Sigma) containing Tris-buffered saline (TBST, in $\mathrm{mM}$; 50 Trizma base, $150 \mathrm{NaCl}, \mathrm{pH}=7.6$ ) and blocked for $1 \mathrm{~h}$ at $\mathrm{RT}$ in $5 \%$ milk powder containing TBST prior to overnight incubations at $4{ }^{\circ} \mathrm{C}$ with primary antibodies (see Supplementary Table 2) under continuous agitation. Antigen-antibody coupling was visualised using appropriate secondary antibodies conjugated to horseradish peroxidase (goat anti-mouse IgG or IgM, goat anti-rabbit IgG; 1:5000, Merk Millipore, Watford, UK) and enhanced chemiluminescence $(1.25 \mathrm{mM}$ Luminol, $30 \mu \mathrm{M}$ coumaric acid, $0.015 \% \mathrm{H}_{2} \mathrm{O}_{2}$ ). All steps were followed by multiple washes in TBST. Processed blots were subsequently stained for measurements of total protein using Coomassie total protein stain (as described previously [65]). Images were captured via Vilber-FusionSL camera (Vilber, Eberhardzell, Germany) at 8-bit for illustration and 16-bit for analysis.

To ensure specificity of the detected signal, appropriate secondary antibody control dot blots were conducted, in which the primary antibody was excluded. For all cases, no detectable immunoreactive signal was observed for either $\mathrm{IgG}$ or IgM secondary antibody isotype in images captured following exposure times of up to $3 \mathrm{~min}$, which was the maximal exposure time required for signal detection in this study (data not shown). 


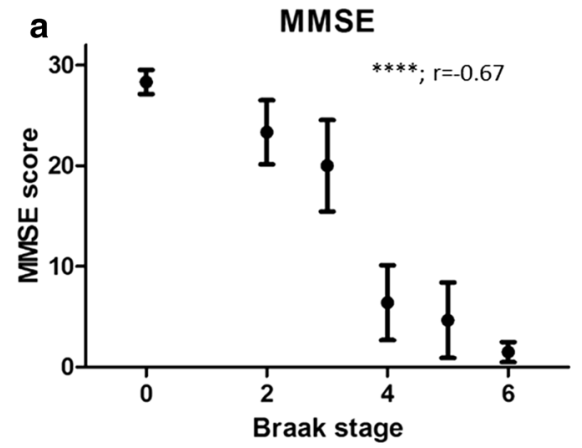

Fig. 1 Cognitive performance during disease progression. Assessment scores from 'Mini Mental State Exam' (MMSE, a) as well as global and memory scores from the 'Clinical Dementia Rating' $(\mathrm{CDR}, \mathrm{b})$ are correlated with disease progression based on Braak

\section{Immuno-quantification}

Immunoreactivity was quantified from 16-bit digitised images using ImageJ (Ver 1.47, NIH, USA) based on area under curve (AUC) measures normalised to total protein load established via AUCs for Coomassie processed blots. Immunoblot intensity data were normalised within blots using total protein adjusted values and expressed relative to appropriate control groups (outlined below), before being pooled across blots.

\section{Cohort stratification}

To determine the relationship of investigated markers to the neuropsychological and pathological processes of $\mathrm{AD}$, cases were grouped into several classifications as follows (see also Table 1):

1. Post-mortem confirmed clinical diagnosis, essentially equating to non- $\mathrm{AD}$ cases $(=\mathrm{Braak}(\mathrm{Br}) 0-3)$ and $\mathrm{AD}$ $(=\mathrm{Br} 4-6)$.

2. Grouped Braak stages: low, intermediate and high severity of Braak pathology ( $\mathrm{Br} 0-2, \mathrm{Br} 3-4$ and $\mathrm{Br}$ 5-6, respectively).

3. Individual Braak score: cases listed per individual stages and normalised to a single Braak score ( $\mathrm{Br} 2)$.

\section{Statistical analysis}

Statistical analysis was performed using Prism (V.6, GraphPad). Data were subject to Shapiro-Wilk test for normal distribution prior to statistical analysis of significance between groups. Individual comparisons were analysed using either a Student's two tailed $t$ test or Mann-Whitney if determined non-parametric. Multiple group comparisons were established via 1-way analysis of variance (ANOVA) or the non-parametric Kruskal-Wallis ANOVA, if reported as significant, selected pair comparisons were conducted

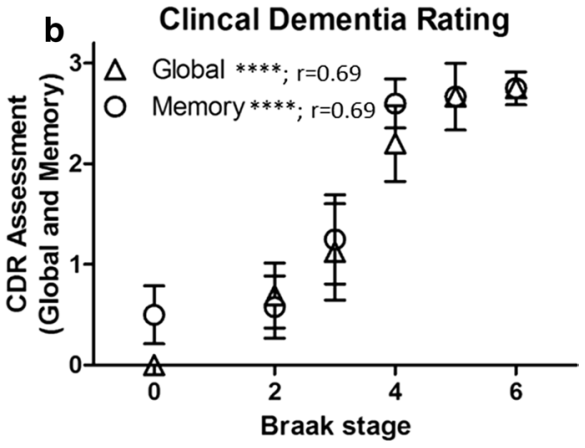

stage. Significances $(p)$ and Spearman's correlation index $(r)$ are provided within each graph. Data are expressed as mean \pm SEM, $* * * * p<0.0001$

via post hoc Bonferroni or Dunn's tests, respectively. Analysis of covariance (ANCOVA) was employed to control for PMI and tissue $\mathrm{pH}$ (Minitab 17). Correlation analysis was conducted using Spearman's ranks correlation, which does not assume normality of data sets. Having established either positive or inverse correlation of markers in relation to Braak stages, individual Braak stages were probed for significant deviation from Braak 0 via a one-tailed $t$ test. For all tests, $p<0.05$ was taken as significant with subsequent levels of statistical reliability reported for $p<0.01$, $p<0.001$ and $p<0.0001$.

\section{Results}

\section{Demographic data and cognitive scores}

Prior to the investigation of pathological markers, biographical data and post-mortem interval were investigated for potentially confounding factors with regards to pathological measures. Independent of analytical classification no significant difference in age, PMI or frontal cortical $\mathrm{pH}$ was determined between groups (Table 1). With the exception of Braak stage 0 (100\% male) and Braak stage 5 (83.3\% male), the cohort was reasonably balanced for gender. Scores of cognition as established by the MMSE (Fig. 1a, $r=-0.67, p<0.0001, n=42$ ), CDR global (Fig. $1 \mathrm{~b}, r=0.69, p<0.0001, n=43$ ), CDR memory (Fig. 1b, $r=0.69, p<0.01, n=43$ ) and CDR sum of box scores (data not shown, $r=0.55, p<0.001, n=33$ ) closely followed Braak stage progression, but not age (data not shown).

\section{Quantification of tau pathology}

Initially, phospho-tau pathology was investigated via immunoblots of soluble lysate, established to selectively extract 


\section{Phospho-Tau Marker}

\section{a $\quad$ AT8}
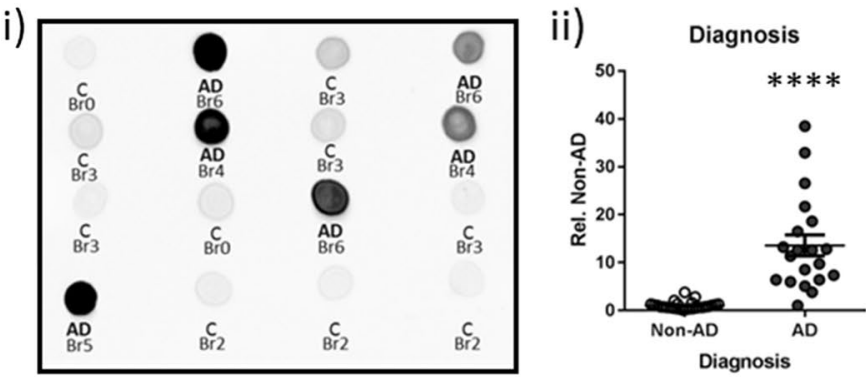

b PHF-1
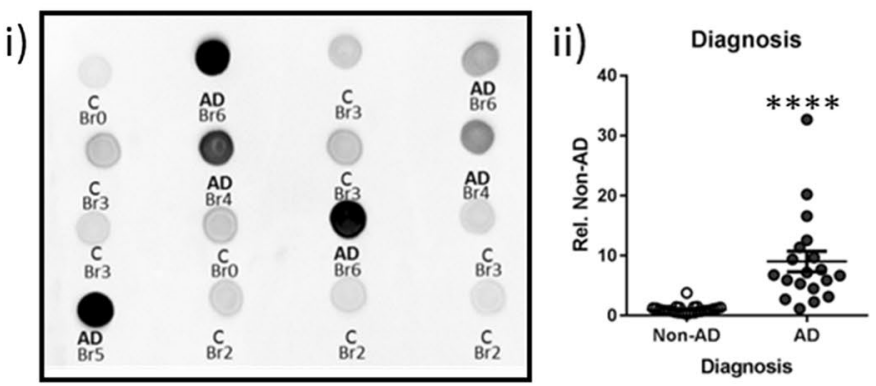

\section{C $\mathrm{CP13}$}
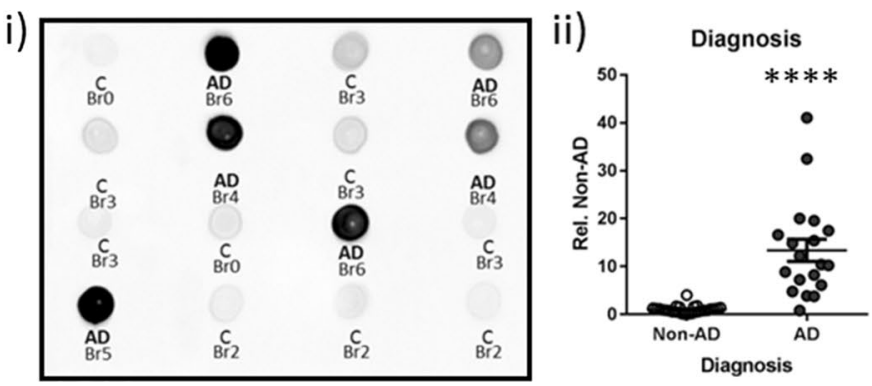
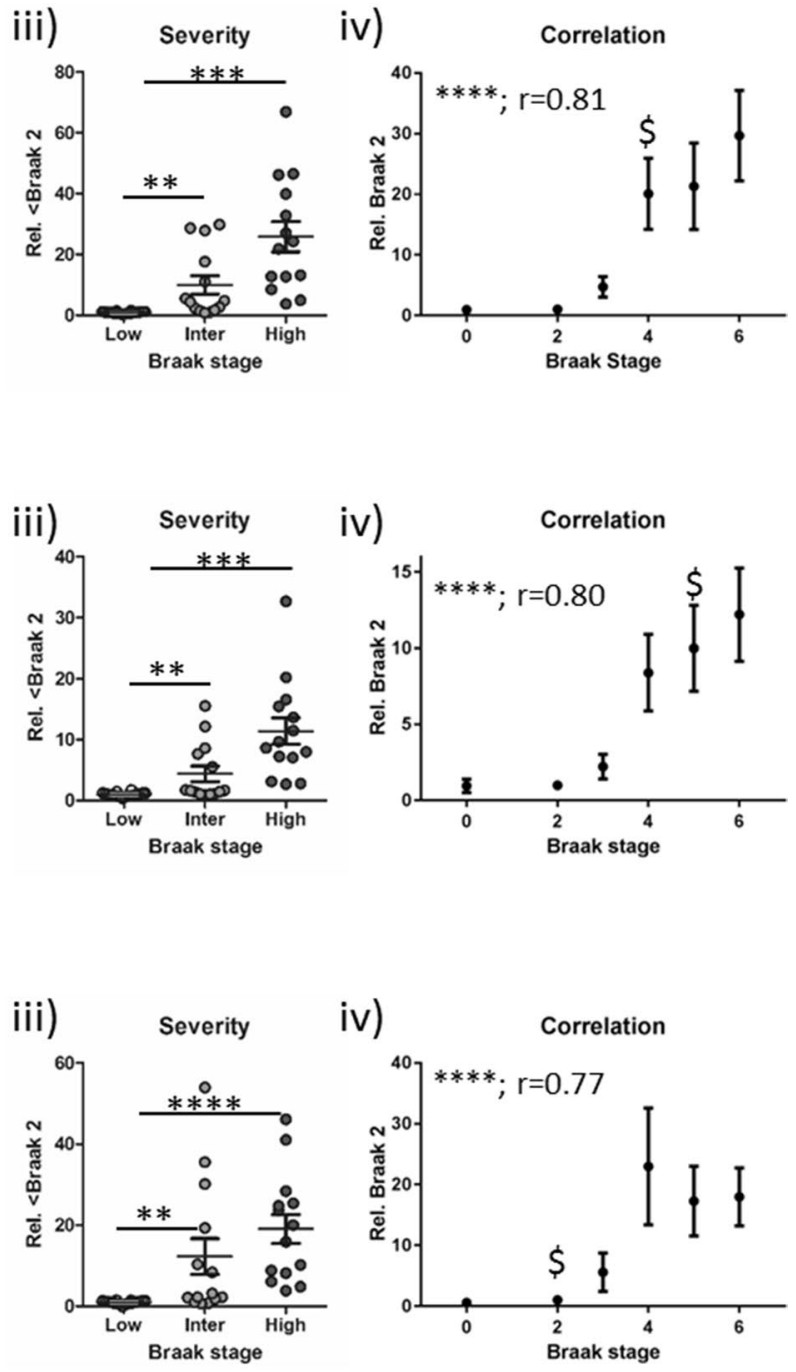

Fig. 2 Phospho-tau pathology. Dot blots for a AT8, b PHF-1, c CP13 phospho-tau immunoreactivity. Cases within example dot blots are labelled for diagnosis [non-AD control cases (' $C$ ') and $A D$ ] and Braak stage $(\mathrm{Br})$. Analyses stratified for ii) diagnosis, iii) severity (Low: $\mathrm{Br}$ 0-2, Intermediate (Inter): $\mathrm{Br} 3-4$ and High: $\mathrm{Br}$ 5-6), and

non-fibrillar protein species (see Supplementary Figure 1). The phospho-specific antibody AT8 recognises tau phosphorylated at serine 199, serine 202 and threonine205 residues (p-ser199/ser202/thr205) [9, 27] and is commonly employed by pathologist for post-mortem confirmation of $\mathrm{AD}$ diagnosis and for the staging of tau pathology according to Braak stage. Under dot blot conditions, which negate alterations in the electrophoretic mobility of tau between samples, due to different degrees of protein phosphorylation [17] and allows for quantification of total tau species phosphorylated at each investigated epitope, AT8 immunoreactivity was strongly enhanced in $\mathrm{AD}$ diagnosed cases, (iv) correlation with individual Braak stages are shown. Statistical outcomes are depicted as $* * p<0.01$, ***p $<0.001, * * * * p<0.0001$ and Spearman's correlation $(r)$. The earliest Braak stage at which immunoreactivity was significantly elevated from Braak 0 is also indicated (\$)

reporting a 14 -fold increase compared to non-AD samples (Fig. $2 \mathrm{a} \mathrm{i}+\mathrm{ii}, p<0.001$ ). A graded increase in AT8 phospho-tau was also observed across grouped Braak stages (Fig. 2aii, low: $\mathrm{Br} 0-2$, intermediate: $\mathrm{Br} 3-4$, high: $\mathrm{Br} 5-6$, $p<0.0001)$. Post hoc analysis demonstrated significant elevations between low and intermediate $(p<0.01)$ and low and high classifications $(p<0.0001)$, yet not between intermediate and high $(p>0.05)$. In accordance with the use of AT8 for the histopathological classification of tau pathology, dot blot quantification of soluble AT8 phosphotau demonstrated a strong correlation with Braak staging (Fig. 2aiii, $r=0.81, p<0.0001$ ), initial elevations of AT8 
phosphorylation being reported as significant from Braak 0 at Braak $4(p<0.05)$, which is in line with Braak stage progression for Brodmann area 21, reportedly affected at Braak stage 4 [2].

Tau phosphorylation was further investigated using two other commonly employed phospho-tau antibodies, PHF-1 (Fig. 2b, p-ser396/ser404) and CP13 (Fig. 2c, p-ser202). As for AT8, PHF-1 and CP13 reactivity was increased in AD compared to non-AD cases (Fig. 2bii + cii, 9- and 13-fold increase for PHF-1 and CP13, respectively, $p<0.0001$ for both). Both PHF-1 and CP13 levels also increased with pathology severity (Fig. 2 biii + ciii, $p<0.0001$ ), reporting elevations within intermediate and high Braak stages compared to low pathology cases. Also, strong correlations with individual Braak stages were observed with PHF-1 and CP13 (Fig. 2biv + civ, $r=0.80, p<0.0001$ for PHF-1 and $r=0.77, p<0.0001$ for CP13). For the three phospho-epitopes, $\mathrm{CP} 13$ changes were detected earliest (Br 0 cf. $\mathrm{Br} 2: p<0.05)$ and PHF-1 latest (Br 0 cf. $\mathrm{Br} 5$, $p<0.05)$. Phospho-tau dot blots were validated for specificity by means of correlation of immunoreactivity with traditional Western blots in a subset of cases for PHF-1 ( $r=0.79, p<0.0001, n=18$, data not shown). A significant effect of Braak stage $\left(F_{(5,80)}=10.47, p<0.0001\right)$ and epitope $\left(F_{(2,80)}=8.61, p<0.001\right)$ and an interaction $\left(F_{(10,40)}=2.43, p<0.05\right)$ was reported when comparing the phospho-epitope specific antibodies, likely due to the variable magnitude of hyperphosphorylation and differential antibody affinities apparent between Braak stages 2-4. Nevertheless, further analysis demonstrated a robust effect of subject matching, indicating those cases with high AT8 staining also demonstrated high levels of CP13 and PHF-1 staining. This is perhaps unsurprising given the similarity of dot blot immunostaining between epitopes (see example blots in Fig. 2).

\section{Conformational and oligomeric tau}

Although hyperphosphorylation is the most extensively studied aspect of tau pathology, several additional protein modifications offer further key parameters in disease pathology. Conformational changes in the natively unfolded structure of the tau protein, leading to an interaction of the $\mathrm{N}$-terminal domain with the microtubule binding domain (MTBD), may be closely modulated by phosphorylation status [81].

Alz-50 was the first antibody derived from paired helical filaments to recognise such a conformational change [37]. Here, its immunoreactivity was unaltered between Non-AD and AD cases ('diagnosis') and did not increase when considered across grouped Braak stages (Fig. 3ai-iii, $p<0.05$ ). Despite a failure to detect differences between diagnosis and severity groups, a modest correlation between
Alz-50 and Braak stage was observed (Fig. 3aiv, $r=0.32$, $p<0.05$ ), likely driven by the increase between individual stages (note $\mathrm{Br} 2$ elevation compared to $\mathrm{Br} 0, p<0.01$ ). The use of the Alz-50 antibody may be confounded by its cross-reactivity with an uncharacterised developmentally regulated protein (Foetal Alz-50-reactive 1 clone protein, FAC1) [14], thus tau conformational changes were further probed with the related MC-1 antibody, which does not cross-react with FAC1 [37]. MC-1 immunoreactivity was distinct from that of Alz-50, detecting a highly selective signal in AD cf. Non-AD cases (Fig. 3bi + ii, $p<0.0001$ ) and was enhanced in accordance with grouped Braak stages (Fig. 3biii, $p<0.0001$ ), principally derived from the level of reactivity within the high category (low cf. high: $p<0.001$; intermediate cf. high: $p<0.01)$. A strong correlation with MC-1 positive conformational tau and Braak stage was apparent (Fig. 3b, $r=0.60, p<0.0001$ ), and determined as elevated from $\geq \mathrm{Br} 4$ relative to $\mathrm{Br} 0$ $(p<0.05)$.

In addition to the emergence of conformational tau pathology, formation of oligomeric tau species has been proposed to correlate with behavioural deficits in animal models [7] and was also previously reported to be elevated in human $\mathrm{AD}$ cases $[40,64,79]$. TOC1 binds to a conformation-dependent epitope preferentially exposed upon oligomerisation (aa209-224) [79], and here recognised a single band when tested in Western blot applications under non-denaturing conditions (no DTT or boiling, 180 kDa; Fig. 3c i, for full blot see Supplementary Figure 2). This band was previously established via SELDI-TOF MS as a tau dimer [63]. TOC1 immunoreactivity was characterised in all cases via native state dot blots (Fig. 3cii) and robustly increased for AD compared to non-AD cases (Fig. 3ciii, $p<0.0001)$, significantly tracked across grouped Braak stages (Fig. 3civ, $p<0.0001$ ) and correlated with individual Braak stage (Fig. 3cv, $r=0.59, p<0.0001$ ). Relative to Braak stage 0 a significant elevation in reactivity emerged at Braak stage $5(p<0.05)$, although in a subset of cases a strong signal prior to this was apparent ( $\mathrm{Br} 4 \mathrm{cf}$. $\mathrm{Br} 0$, $p=0.07)$.

\section{Correlations of tau biomarkers}

Correlative analysis of each pathological tau marker within our soluble preparation demonstrates a variable degree of agreement between all tau markers, with the exception of Alz-50 (Table 2). Interestingly, prominent markers for conformational and oligomeric tau yielded high correlations with differential phosphorylation epitopes (MC-1 with PHF-1 and TOC1 with CP13). No correlation with PMI, cortical $\mathrm{pH}$ or age was observed with any of the markers tested; this was further confirmed by ANCOVAs (all $p$ 's $>0.05$ ). 


\section{Conformational Tau}

\section{a Alz-50}
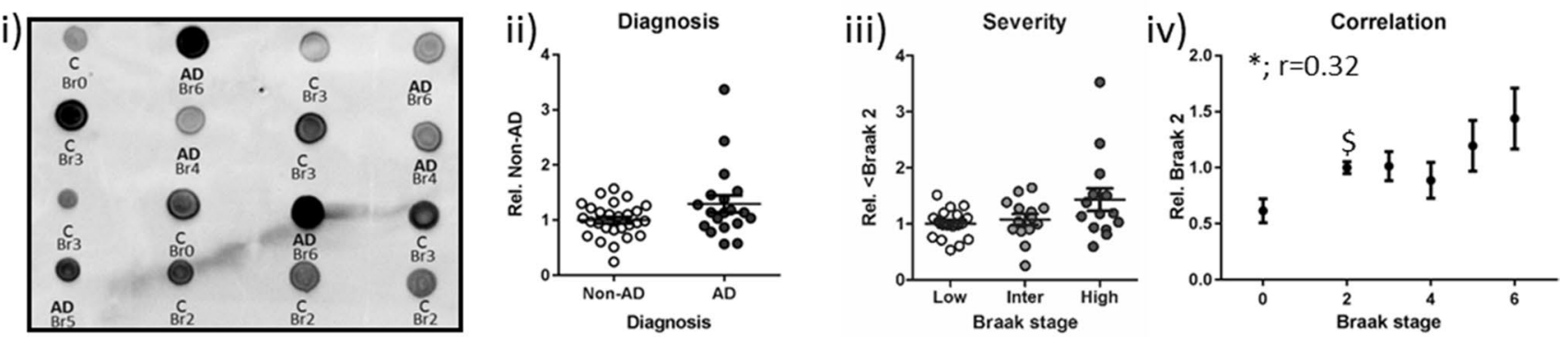

b MC-1
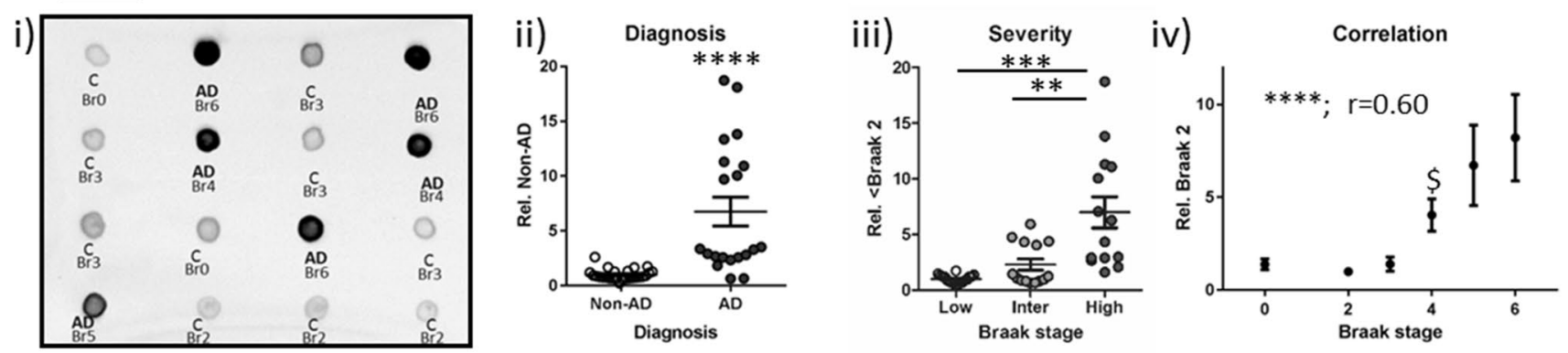

\section{c Oligomeric Tau (TOC1)}

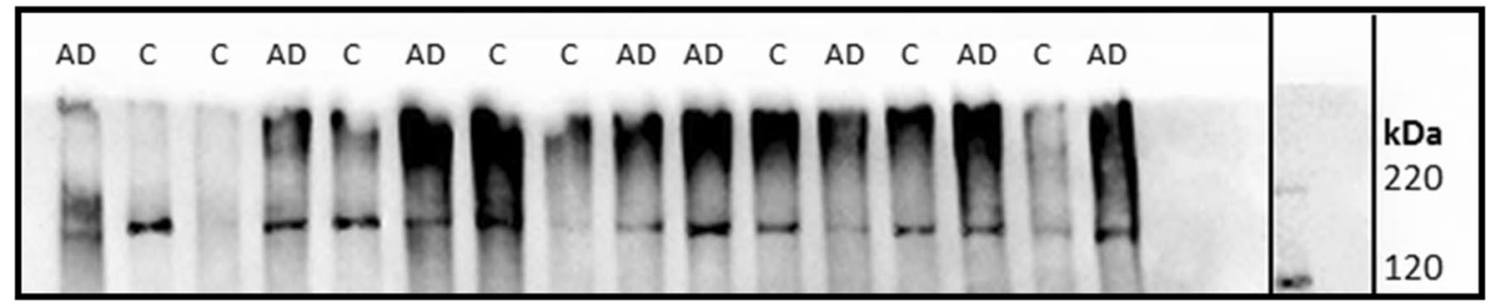

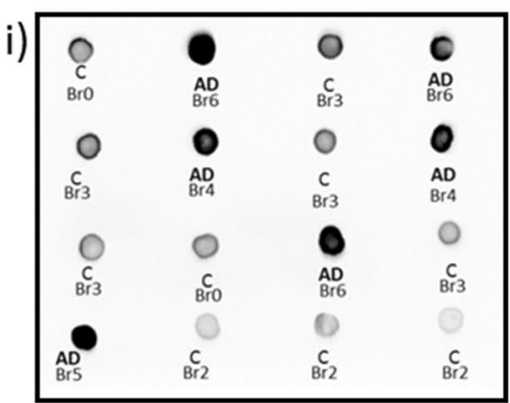

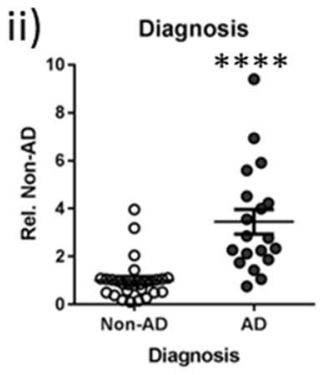

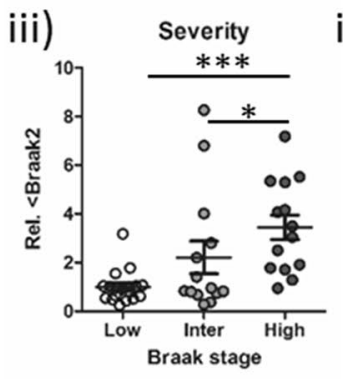

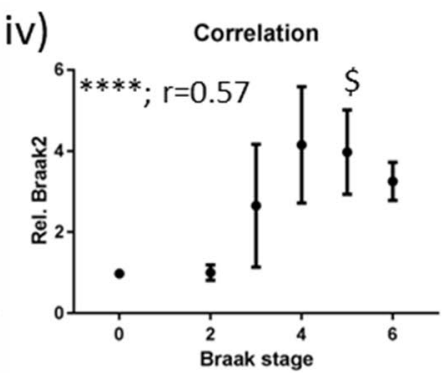

Fig. 3 Conformational and oligomeric tau pathology. a Alz-50 and b MC-1 conformational tau and coligomeric tau (tau-oligomeric-complex 1; TOC1) dot blots. The inset $(C)$ illustrates an example Western blot for TOC1 run under non-reducing, non-denaturing conditions, labels show diagnosis status ( $C=$ non-AD and $A D)$. In $A-C$, quantifications of immunoreactivity is categorised according to diagnosis (ii), severity (iii, low: $\mathrm{Br} 0-2$, intermediate (Inter): $\mathrm{Br} 3-4$ and High: $\mathrm{Br}$ 5-6) and correlation with Braak stage (iv). Significances are indicated as follows: $* p<0.05, * * p<0.01, * * * p<0.001, * * * * p<0.0001$ and Spearman's correlation $(r)$. The lowest Braak stage at which immunoreactivity was significantly elevated from Braak 0 is indicated by $\$$ 
Table 2 Correlations of tau pathology markers

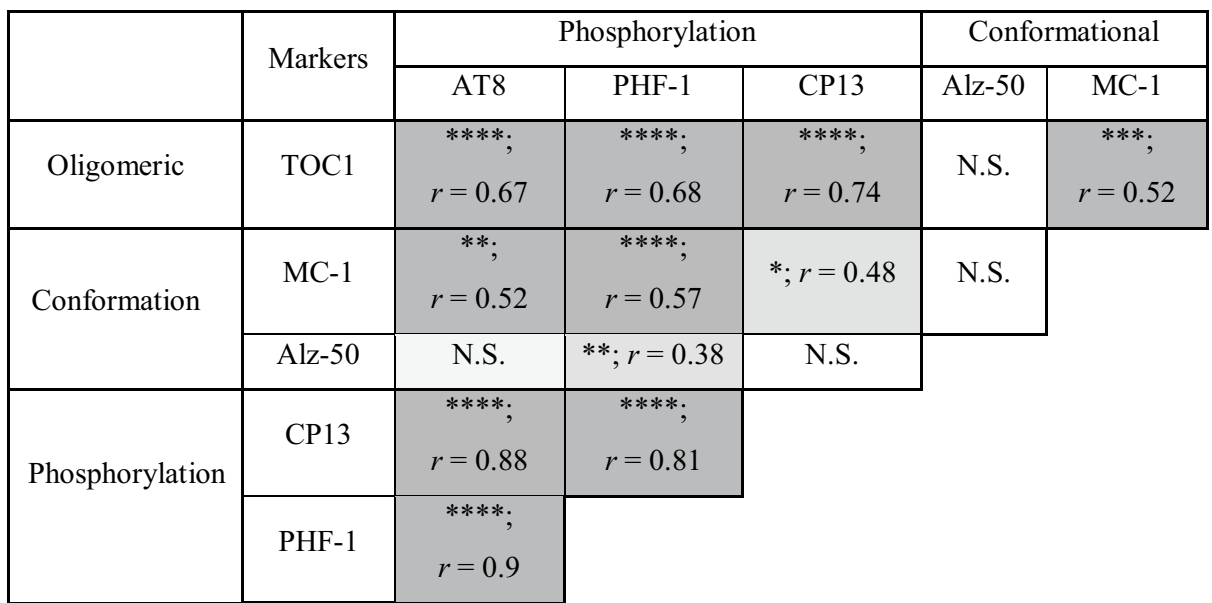

Results are organised according to tau species subtypes and antibodies used

Significances $(p)$ and outcome from Spearman's correlation $(r)$ between each marker and statistical reliability are shown and visualised by means of graded shading. $* p<0.05, * * p<0.001$, $* * * p<0.001$ and $* * * * p<0.0001$. N.S. not significant

\section{APP processing and pathology}

\section{Amyloidogenic processing}

Immunoblotting with the commonly used antibody $6 \mathrm{E} 10$, which is raised towards the human $A \beta_{1-16}$ sequence, produced multiple bands in Western blots corresponding to various APP metabolites as well as full-length APP (fAPP). The major 6E10 immunoreactive band migrated between 80 and $120 \mathrm{kDa}$ and was consistently observed in lysates from human samples and a hAPP overexpressing mouse (Fig. 4a i). This primary band equates to various post-translational modified species of fAPP and was evidently reduced between $\mathrm{AD}$ and non-AD cases (Fig. 4a ii, $p<0.05$ ) but failed to reach significance across grouped Braak stages (Fig. 4a iii, $p=0.09$ ). Levels of fAPP did, however, correlate (negatively) with the progression of Braak stage (Fig. 4a iv, $r=-0.39$, $p<0.01$ ); post hoc analysis indicated this to be due to a significant reduction in the levels of fAPP as early as Braak stage 2 ( $p<0.05$ for $\mathrm{Br} 2$ vs $\mathrm{Br} 0)$. Similar trends for the reduced expression of fAPP were also observed following the use of an N-terminal APP directed antibody (see Supplementary Figure 3).

The reduction of fAPP with diagnosis and disease severity may suggest a facilitation of APP cleavage via amyloidogenic secretases in AD cases. Several groups have previously reported a disease-dependent increase in BACE1 and thus a promotion of $\mathrm{A} \beta$ production pathways [24, 34]. However, despite the decrease of fAPP, BACE1 expression levels were unaltered in any of the analytical stratifications (Fig. 4b; $p>0.05$ for all).

\section{A $\beta$ species}

The detection of $\mathrm{A} \beta$ species, from monomers to oligomers, is problematic due to a number of confounding factors such as the cross-reactivity of many $A \beta$-directed antibodies with similar-sized non-A $\beta$ APP metabolites and the potential for experimental parameters to modify $A \beta$ self-oligomerization [80]. Probing standard Westerns blots with 6E10 detected immunoreactive bands migrating at $4 \mathrm{kDa}$ equating to monomeric $\mathrm{A} \beta$ and $12 \mathrm{kDa}$ band potentially equating to trimeric $\mathrm{A} \beta$ or $\mathrm{C}$-terminal fragments of APP. The $12 \mathrm{kDa}$ band was not quantified here, but also was detected in lysates from hAPP overexpressing mice, yet absent in wild-type mouse lysates (see example in Fig. 5a i). Initial quantification of monomeric $\mathrm{A} \beta$ (all cases), demonstrated a $\sim 6$-fold increase in monomeric $\mathrm{A} \beta$ levels in $\mathrm{AD}$ relative to non-AD cases (Fig. 5a ii, $p<0.0001$ ) and an overall effect of grouped Braak stages (Fig. 5a iii, $p<0.001$ ). Post hoc analysis demonstrated that significance was principally driven by the elevation at late stages $(\mathrm{Br} \leq 2 \mathrm{cf}$. $\mathrm{Br} \geq 5$, $p<0.001$ and $\mathrm{Br} 3-4$ cf. $\mathrm{Br} \geq 5, p<0.001)$. Interestingly, a strong correlation with Braak stage was also established ( $r=0.57, p<0.0001)$ but the increased $\mathrm{A} \beta$ immunoreactivity did not reach significance from Braak stage 0 until stage $5(p<0.01)$.

Quantification of monomeric $\mathrm{A} \beta$ based on all cases is questionable as it relies on the inclusion of data from samples lacking a discernible band (i.e. signal value near background). The absence of detectable soluble $\mathrm{A} \beta$ in mildly dissociated tissues (manual homogenisation as opposed to sonification) using Western blots has previously been established [38], therefore, quantification in 
a Full length APP (fAPP)

i)

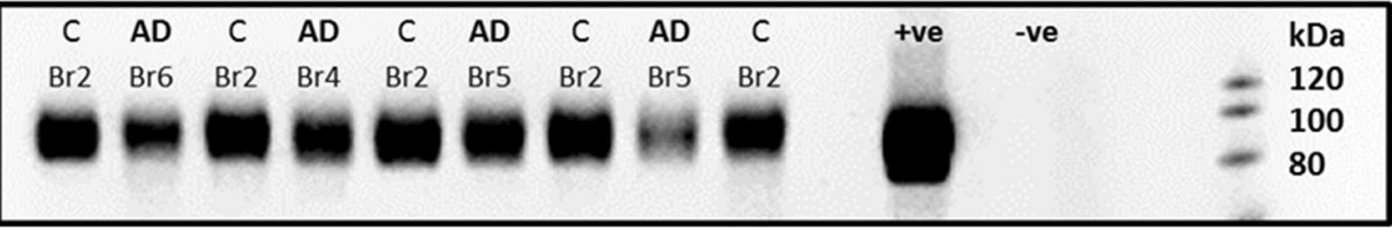

ii)

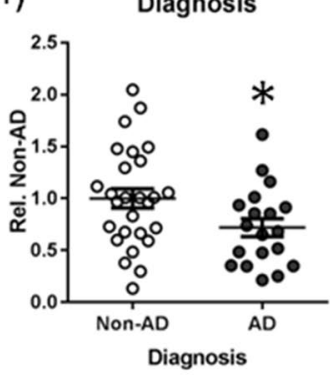

iii) Severity

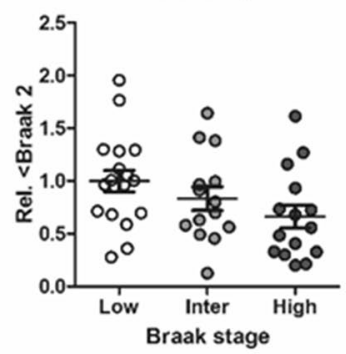

iv)

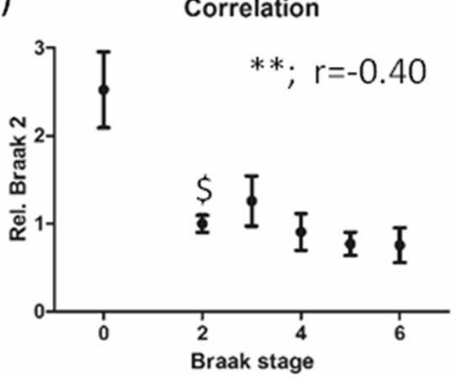

b BACE1
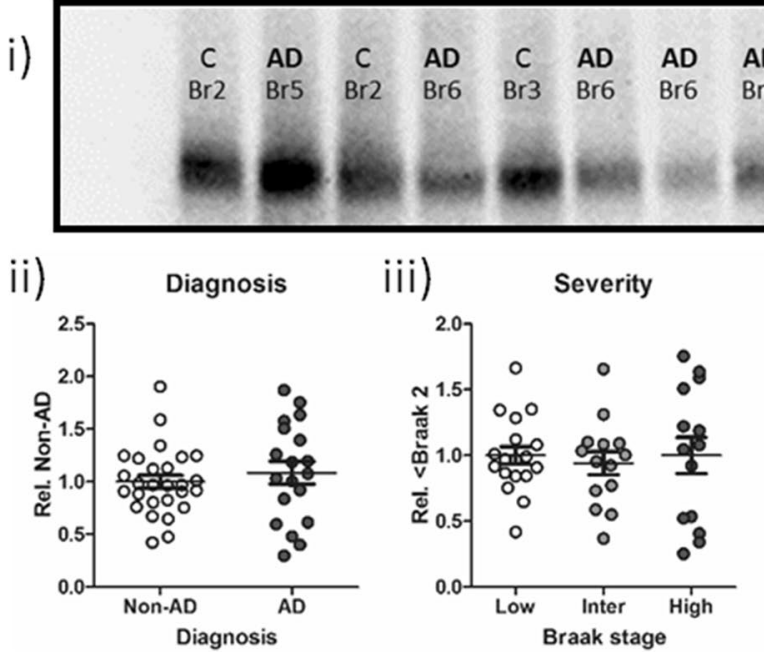

$\mathrm{kDa}$

80

60

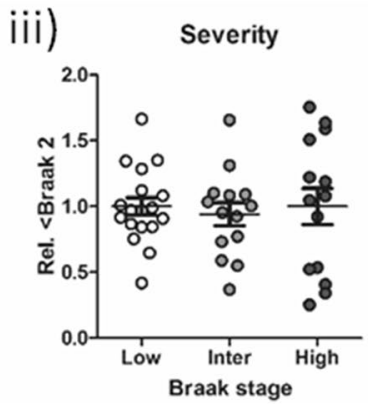

iv)

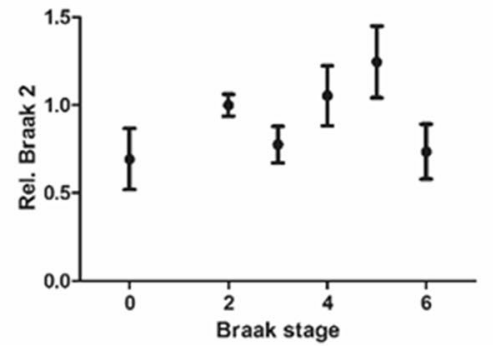

Fig. 4 Amyloid precursor protein cleavage. Exemplary Western blots for a full-length APP detected via 6E10 immunoreactivity, and b $\beta$-secretase (BACE1) are illustrated. Braak stage (Br) and diagnosis (non-AD $(C)$ cf. $A D)$ are stated above each sample. Positive (+ve) control: human APP overexpressing mouse and negative (-ve) control (in a: wild-type C57/BL6 mouse and in b: BACE1 $1^{-1-}$ mouse) are included. Total protein normalised immunoblot signals were analysed

this fashion cannot be considered technically robust. Others have employed direct measurements using densitometry (for example [49, 67]), but failure to adjust for inter-blot differences in background and signal intensity may introduce additional noise into the data. More appropriate analysis arises from monomeric $A \beta$ levels quantified only for those samples in which a band can be clearly detected (16 out of 19 AD samples, 14 out 27 non-AD samples). With this approach (termed monomeric $A \beta$ positive, Fig. $5 \mathrm{c}$ i), monomeric $\mathrm{A} \beta$ was confirmed to be elevated for $\mathrm{AD}$ diagnosed cases relative to Non-AD controls $(p<0.01)$ and according to diagnosis (ii), severity (iii, low: $\mathrm{Br} 0-2$, intermediate (Inter): $\mathrm{Br} 3-4$ and high: $\mathrm{Br} 5-6)$ and Braak stage correlation (iv). Statistical results are presented as $* p<0.05, * * p<0.01$ and Spearman's correlation $(r)$ are stated in the graphs. $\$$ indicates the lowest Braak stage at which immunoreactivity differed significantly from Braak 0

demonstrated a significant effect of grouped Braak staging (Fig. 5c ii $p<0.001$ ), yet post hoc analysis demonstrated only a significant elevation between Braak stage 3-4 and 5-6 $(p<0.001)$ but not Braak stages 0-2 $(p>0.05)$. Normalisation of the data set to Braak stage 2 was not possible due to the inconsistent detection of monomeric $A \beta$ within cases of low-stage pathology. Other higher molecular $A \beta$ aggregates have attracted attention in the past, for example, the frequently reported dodecameric $A \beta * 56$ [48, 49]. A corresponding band was detected here following longer exposure times, which revealed several additional bands on 
a $\mathrm{A} \beta$ Monomers

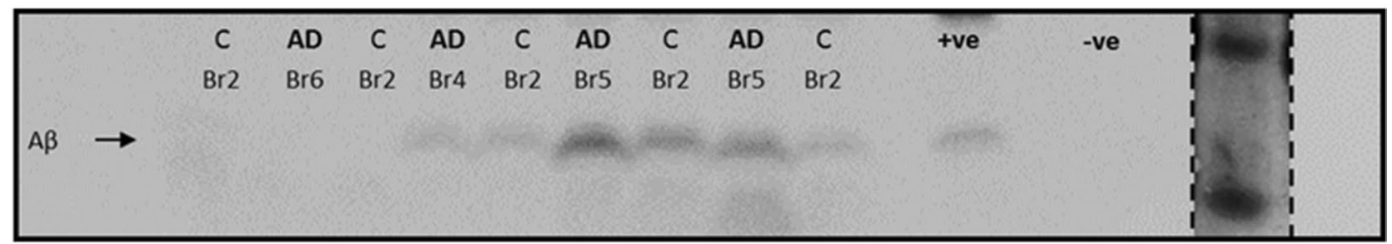

b Monomeric $A \beta$ (all cases)

i)

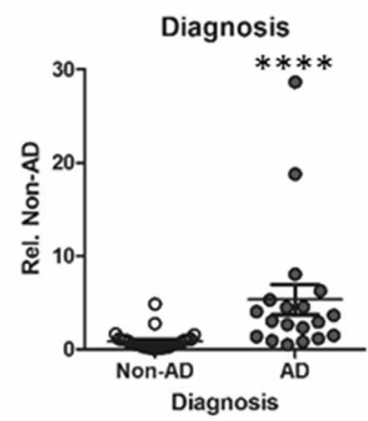

ii)

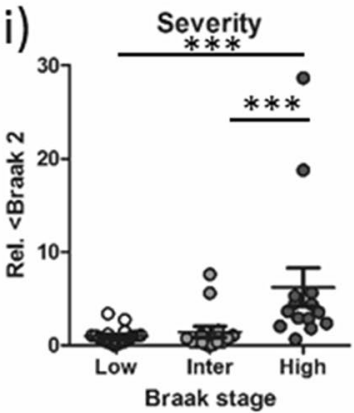

iii)

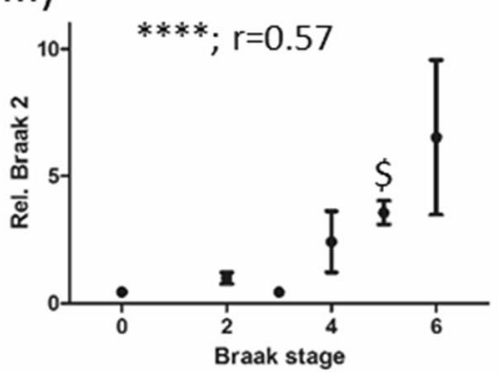

C Monomeric $A \beta$ (positive)

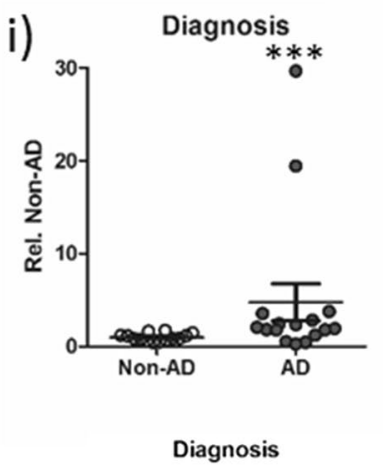

Fig. 5 Monomeric $\beta$-amyloid (A $\beta)$. Immunoblot for a monomeric $\mathrm{A} \beta$ (6E10 antibody). Diagnosis (Non-AD $(C)$ cf. $A D$ ) and Braak stage is stated for each case. Positive (+ve) control: human APP overexpressing mouse and negative $(-\mathrm{ve})$ control (wild-type mouse) samples are also shown. Size comparison was established via a Coomassie stained low molecular weight protein ladder (insert). Quantification was conducted either for all cases (b) or only for samples where a band was evident (c), the percentage (\%) of cases in

Western blots probed with 6E10 (Fig. 6a). In a subset of cases $(n=16)$, we attempted to quantify and validate the *56 band. Although no significant difference between diagnosis or severity groups could be established (Fig. 6b i-ii), an apparent decline in $* 56$ levels with Braak stage was observed (Fig. 6b iii) in agreement with previous reports [49]. However, Western blot protocols pose several technical issues for the identification of $A \beta$ oligomers due to species modifications induced by reducing agents and heating of samples. Therefore, samples were also run under quasi non-denaturing conditions as conducted for TOC1. Under these near-native state conditions (Fig. 6a), the detection

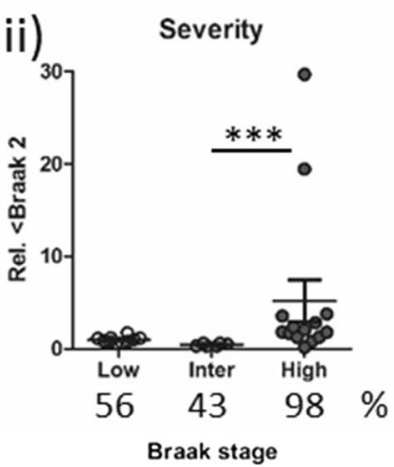

which monomeric $\mathrm{A} \beta$ was detected is stated below the graph. Total protein adjusted immunosignal stratified to i) diagnosis ii) severity (Low: $\mathrm{Br} 0-2$, Intermediate (Inter): $\mathrm{Br} 3-4$ and High: $\mathrm{Br} 5-6$ ) and iii) correlation with individual Braak stage. Significances are illustrated as $* * * p<0.001, * * * * p<0.0001$, Spearman's correlation is also stated. \$: indicates the earliest Braak stage at which immunoreactivity was higher than that observed at Braak stage 0

of $* 56$ was greatly diminished and no consistent alteration was observed in any analytical stratification for any group (Fig. $6 \mathrm{a}+\mathrm{c}$ ), indicative that potential artefacts induced by standard SDS-PAGE methods had likely modified native $\mathrm{A} \beta$ species.

As an alternative means of quantifying soluble $A \beta$ load, non-denaturing dot blots were stained with the $A \beta$-selective antibody MOAB-2, which does not cross-react with APP or other metabolites [77]. Here, $A \beta$ was consistently detected in all $\mathrm{AD}$ cases, with levels robustly elevated in diagnosed relative to Non-AD samples (Fig. 7a ii, $p<0.0001$ ); the signal increased progressively across grouped Braak stages 
a Oligomeric $A \beta$ detection

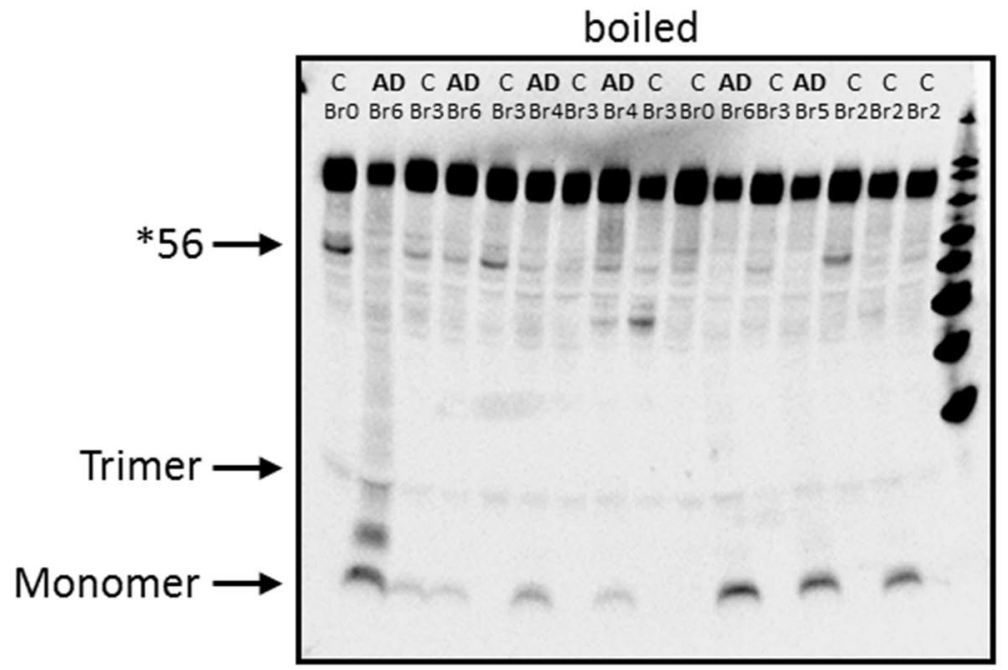

b Oligomeric *56 A 3 (boiled samples)

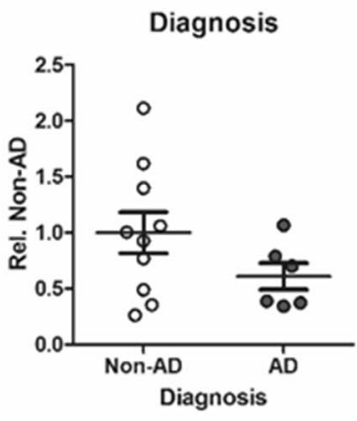

Severity
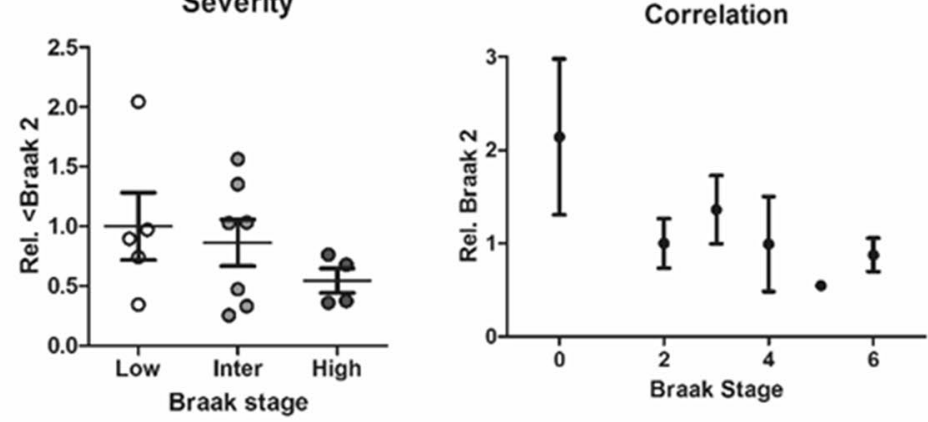

non-boiled

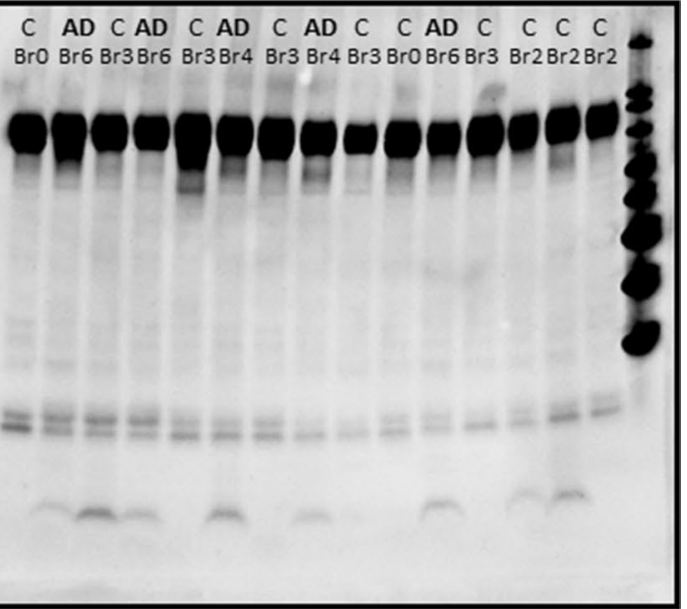

C Oligomeric *56 A 3 (non-boiled samples)
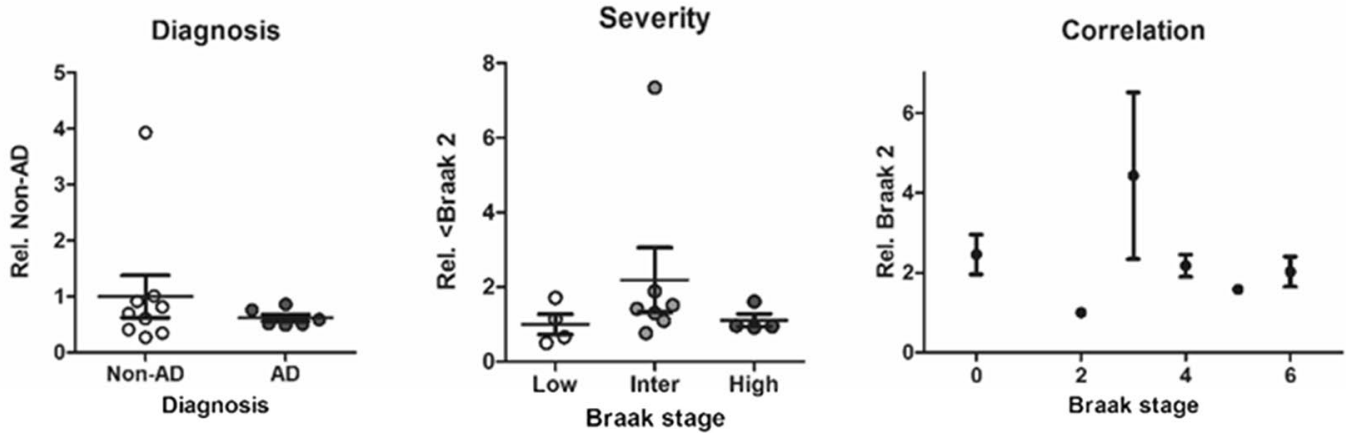

Fig. 6 Heat-dependent detection of $A \beta$ oligomers. a Side by side comparison of 6E10 immunoreactivty following boiling and nonboiling of samples prior to SDS-PAGE separation. Monomeric, trimeric and $* 56 \mathrm{~A} \beta$ bands are indicated alongside individual diagnosis ( $C$ non-AD control and $A D$ cases) and Braak stage $(\mathrm{Br})$ clas- sifications. Quantification of $* 56$ oligomeric $A \beta$ levels according to i) diagnosis, ii) severity (Low: $\mathrm{Br} 0-2$, intermediate (Inter): $\mathrm{Br} 3-4$ and High: $\mathrm{Br} 5-6)$ and iii) correlation to individual Braak stage for boiled (b) and non-boiled (c) samples
(Fig. 7a iii, $p<0.0001$ ). Further statistical comparison revealed strongest elevations in Braak 5-6 cases compared to Braak 0-2 $(p<0.001)$ and Braak 3-4 $(p<0.05)$. The 


\section{Soluble $A \beta$}

a $\mathrm{MOAB}-2$

i)

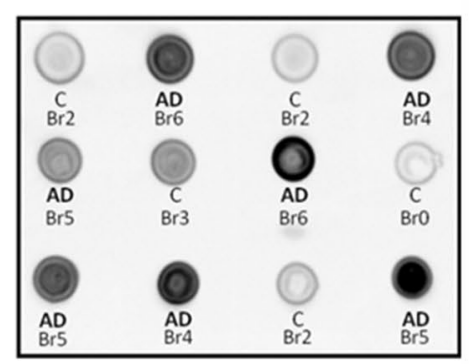

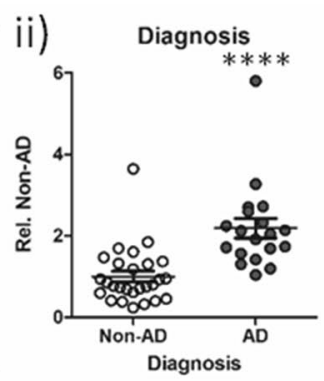

\section{b Pyro-glu}

i)

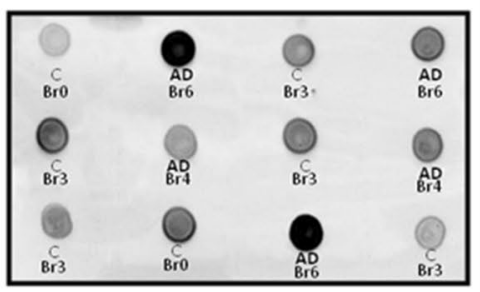

ii)

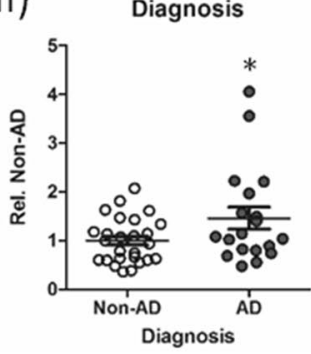

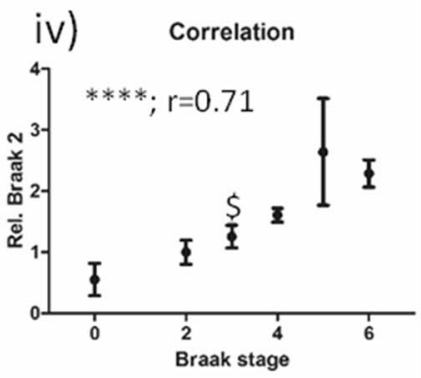

iv) Correlation

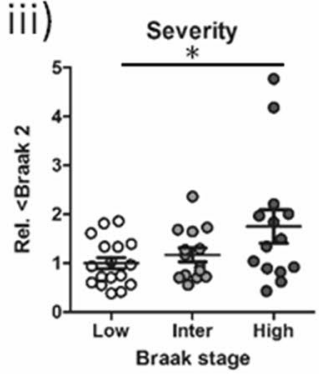

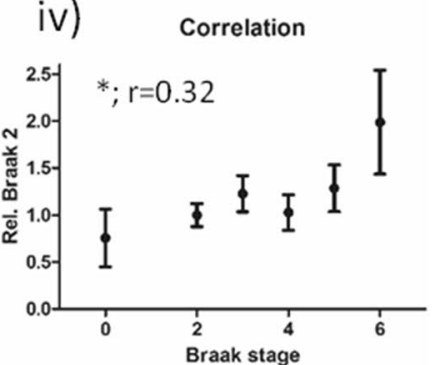

Fig. 7 Soluble $A \beta$ detection. Example immunoblots for $\mathbf{a}$ i) MOAB-2 and $\mathbf{b}$ i) pyro-glu reactive $A \beta$; each case is labelled with corresponding diagnosis [Non-AD $(C)$ cf. $A D]$ and Braak stage. Quantified signals normalised to total protein are shown stratified to ii) diagnosis iii), severity (Low: $\mathrm{Br} 0-2$, Intermediate (Inter): $\mathrm{Br} 3-4$ $p=0.0001)$. MOAB-2 levels were initially detected as enhanced at Braak stage 3 relative to Braak stage 0 $(p<0.05)$.

Next, cases were further probed for post-translational modification of $A \beta$ species with pyro-glu [21]. In Western blots, a single immunoreactive band was identified migrating $\sim 12 \mathrm{kDa}$, which in a subset of samples approached significant elevations based on diagnosis and when samples grouped in low, intermediate and high Braak stages ( $p=0.07$ and $p=0.08$, respectively), but did correlate with individual Braak stages $(r=0.32, p<0.05$; data not shown). When all cases were characterised in non-denaturing immuno-dot blot conditions, pyro-glu $A \beta$ immunoreactivity was enhanced based on diagnosis criteria (Fig. $7 \mathrm{~b}$ $\mathrm{i}, p<0.05$ ), increased in line with grouped Braak stages (Fig. $7 \mathrm{~b}$ ii, $p<0.05$ ) and correlated with individual Braak stage (Fig. 7b iii, $r=0.32, p<0.05$ ). Post hoc analysis indicated that significance was largely driven by late-stage pathological changes ( $\mathrm{Br} 5-6 \mathrm{cf} . \mathrm{Br} \leq 2, p<0.05$ ), yet no individual Braak stage was significantly elevated from $\mathrm{Br} 0$ cases. As can be seen in scatter plots in Fig. 7b, significance was primarily driven by two highly reactive $A D$ and High: $\mathrm{Br} 5-6)$ and iv) correlation with Braak stage. ${ }^{*} p<0.05$, $* * * p<0.001, * * * * p<0.0001$ and Spearman's correlation $r$ is stated in iv. $\$$ denotes lowest Braak stage at which immunoreactivity differed from Braak 0

cases, however, further investigation (Grubb's outlier test) did not report these as significant $(p>0.05)$.

To further characterise the impact of heating on $\mathrm{A} \beta$ and their detection, boiled and unboiled lysates were transferred onto nitrocellulose membranes. Under boiling conditions, the diagnosis-specific increase of $\mathrm{A} \beta$ as detected by MOAB-2 was abolished and even appeared reduced relative to NonAD cases (Fig. 8a i-ii, $p=0.09$ ). The heat-sensitive nature of MOAB- 2 mediated $A \beta$ detection was further confirmed by a two-way ANOVA, comparing across grouped Braak stages (Fig. 8a iii, Braak stages: $F_{(2,26)}=0.83, \mathrm{p}>0.05$, boiling: $F_{(1,26)}=5.9, p<0.01$ and interaction: $\left.F_{(2,1)}=3.8, p<0.05\right)$. In comparison, the detection of phospho-Tau was unaffected by boiling (see Supplementary Figure 4).

\section{Correlation between $A \beta$-related biomarkers}

The various $A \beta$-related markers failed to demonstrate a similar interrelated pattern as observed for tau (Table 3). Nevertheless, fAPP measurements inversely correlated with quantified levels of MOAB- 2 reactive $A \beta$, which itself correlated with monomeric and pyro-glu $A \beta$, as one would expect for 
Fig. 8 Heat sensitivity of soluble A $\beta$ (MOAB-2 epitope). (i) Dot blots of either boiled or non-boiled samples probed with MOAB-2 for oligomeric $\mathrm{A} \beta$. Diagnosis [non-AD $(C)$ and $\mathrm{AD}]$ and Braak stage $(\mathrm{Br})$ are shown for each sample. Matched samples for boiled vs non-boiled conditions were analysed according to diagnosis (ii) and severity (low: $\mathrm{Br} 0-2$, intermediate (Inter): $\mathrm{Br} 3-4$ and high: $\mathrm{Br}$ 5-6) (iii). Statistical outcome of a two-way ANOVA is reported in the corresponding graph. $* p<0.05$ and $* * * p<0.001$

\section{Soluble $A \beta$ (MOAB-2)}
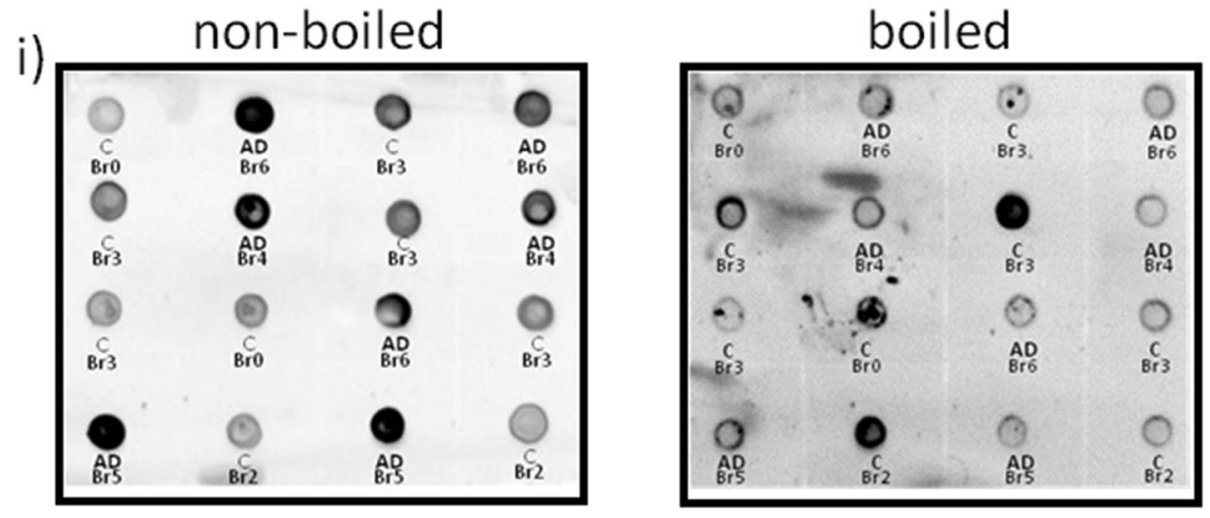

ii)

Diagnosis

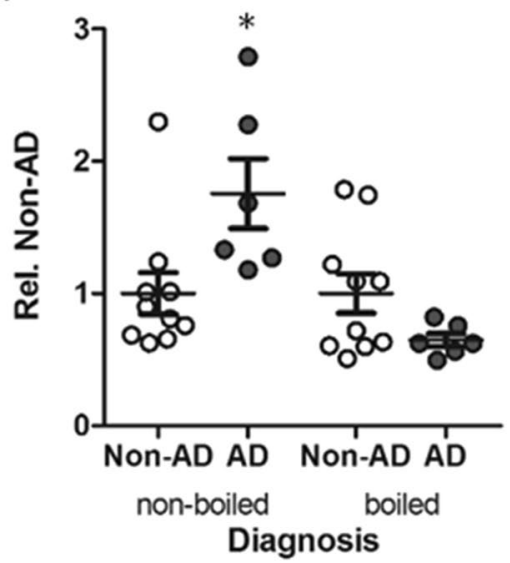

iii)

Severity

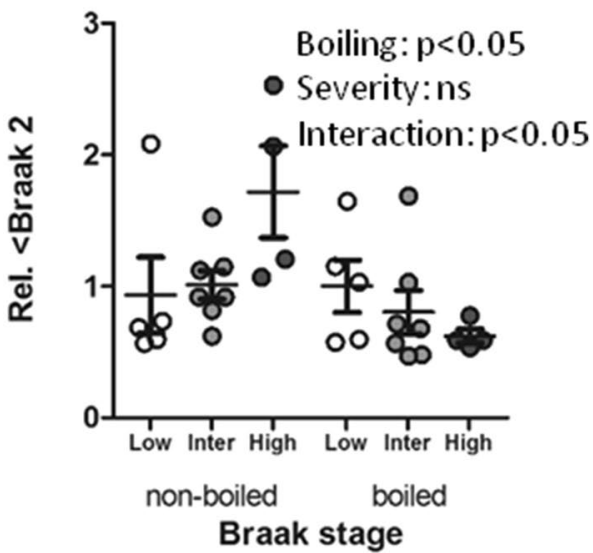

Table 3 Correlations between amyloid pathology markers

\begin{tabular}{|c|c|c|c|c|c|}
\hline & \multirow{2}{*}{ Markers } & \multirow{2}{*}{$\frac{A P P}{\text { fAPP (6E10) }}$} & \multirow{2}{*}{$\begin{array}{c}\text { Secretase } \\
\text { BACE1 }\end{array}$} & \multicolumn{2}{|c|}{$A \beta$} \\
\hline & & & & Pyro-glu & Mono (6E10) \\
\hline \multirow{3}{*}{$A \beta$} & $\begin{array}{c}\text { Soluble } \\
\text { (MOAB) }\end{array}$ & $* ; r=-0.34$ & N.S. & $* ; r=0.31$ & $* ; r=0.34$ \\
\hline & $\begin{array}{l}\text { Mono } \\
(6 E 10)\end{array}$ & N.S. & N.S. & N.S. & \\
\hline & Pyro-glu & N.S. & N.S. & & \\
\hline Secretase & BACE1 & N.S. & & & \\
\hline
\end{tabular}

Components of the amyloidogenic cascade listed are full-length APP (fAPP) as detected via 6E10 APP antibody, $\beta$-secretase (BACE1), monomeric $\mathrm{A} \beta$ (mono $\mathrm{A} \beta)$ as detected by $6 \mathrm{E} 10$, soluble $\mathrm{A} \beta$ as detected by MOAB-2 and pyro-glu $\mathrm{A} \beta$

Significances $(p)$ and Spearman's correlation $(r)$ between each component are provided. $* p<0.05$. N.S. not significant

a signal derived from a metabolite of APP. No correlation or effect of cortical $\mathrm{pH}$ or PMI as covariates was observed for any of the $\mathrm{A} \beta$ markers examined here $(p>0.05)$.

\section{Tau and $A \beta$ : mutual correlations}

The correlations identified for tau and amyloid markers imply a relationship of components within the categories of tau and amyloid species. Determining correlations between these pathologies is of critical importance, particularly in light of the early stage emergence of both soluble tau and amyloid (Table 4). Accordingly, soluble MOAB-2 reactive $A \beta$ was the only $A \beta$-related marker to correlate with all markers of tau pathology, and best matched with phospho-tau markers PHF-1 and AT8 $(r>0.63, p<0.0001$ for 
Table 4 Correlations between tau and amyloid markers

\begin{tabular}{|c|c|c|c|c|c|c|}
\hline & \multirow[b]{2}{*}{ Markers } & \multirow{2}{*}{$\begin{array}{c}A P P \\
\text { fAPP } \\
\text { (6E10) }\end{array}$} & \multirow{2}{*}{$\begin{array}{c}\text { Secretase } \\
\text { BACE1 }\end{array}$} & \multicolumn{3}{|c|}{$A \beta$} \\
\hline & & & & Pyro-glu & $\begin{array}{l}\text { Mono } \\
\text { (6E10) }\end{array}$ & $\begin{array}{l}\text { Soluble } \\
\text { (MOAB) }\end{array}$ \\
\hline Oligomeric & TOC1 & $* ; r=-0.33$ & N.S. & N.S. & $* ; r=0.29$ & $* * * ; r=0.52$ \\
\hline \multirow{2}{*}{ Conformation } & MC-1 & $* * ; r=-0.39$ & N.S. & N.S. & N.S. & $* * ; r=0.38$ \\
\hline & Alz-50 & N.S. & N.S. & N.S. & N.S. & $* ; r=0.34$ \\
\hline \multirow{3}{*}{ Phosphorylation } & CP13 & $* ; r=-0.32$ & N.S. & N.S. & $* ; r=0.32$ & $* * * * ; r=0.63$ \\
\hline & PHF-1 & N.S. & N.S. & $* ; r=0.34$ & $* * ; r=0.41$ & $* * * * ; r=0.64$ \\
\hline & AT8 & $* * ; r=-0.46$ & N.S. & $* ; r=0.37$ & N.S. & $* * ; r=0.45$ \\
\hline
\end{tabular}

Data are organised according to the components of the amyloidogenic cascade (horizontal axis) or tau pathology (vertical axis). Spearman's correlation $(r)$ between each component and statistical strength $(p)$ is shown. Intensity of shading visualises strength of correlation

$* p<0.05, * * p<0.001, * * * p<0.001$ and $* * * * \quad p<0.0001$. N.S. not significant

both). These observations were further strengthened by the reciprocal, inverse correlations of oligomeric (TOC1), conformational (MC-1) and phospho-tau (CP13 and AT8) with total fAPP. In contrast to soluble MOAB-2-reactive $A \beta$, monomeric $A \beta$ and pyro-glu $A \beta$ correlated more selectively with phospho-tau and oligomeric tau epitopes.

\section{Pathological correlates of Braak staging and cognition}

The overall robust correlations of both tau and $A \beta$ markers with Braak stages are summarised in Table 5 and listed alongside associations obtained with cognitive measures. Outcomes were in close agreement with each other, reporting strong correlations with all phospho-tau markers but also with conformational tau (MC-1) and oligomeric tau (TOC1). Critically, for amyloidogenic processing soluble MOAB-2 reactive $\mathrm{A} \beta$ consistently reported a high level of correlation with cognitive decline, approximately matching the correlative strength of tau markers. Monomeric A $\beta$ also strongly correlated with cognitive decline, however, this must be viewed with caution due to the lack of reliable detection in some AD cases.

\section{Discussion}

\section{Taupathology}

Quantification of soluble, abnormally phosphorylated tau detected in brain lysates was highly predictive of the clinical diagnosis and rose with the severity of neuropathological classifications, regardless of the phospho-epitope. In agreement with the stereotypical progression of NFTs over the course of AD, phosphorylation at the AT8 epitope was first significantly elevated at Braak stage 4 [2, 15]. Classically based on the detection of NT and NFTs via argyrophilic stains, modern Braak staging utilises AT8 and thus includes the additional detection of pre-tangle tau. The accumulation of soluble, phosphorylated tau is evident within the temporal cortex and precedes mature tau lesions in many low Braak stage (I-III) cases [2]. Here, tau species detected in our soluble fraction most likely reflect changes within pre-tangle neurons rather than NF and NFTs, and already appeared at Braak stage 2 (CP13). All three phospho-tau antibodies strongly correlated with Braak stages, in close agreement with previous reports [84]. This was nevertheless surprising given the well-documented postmortem reduction in phosphorylation [23], largely due to the energy-independent activity of phosphatases. Although samples used in the current study had longer PMIs compared to those from some previous publications, no impact of PMI as covariate or correlation of any marker with PMI was observed. Moreover, no evidence for protein degradation was detected in either blotting techniques. Ultimately, the long PMIs may have resulted in an under-estimation of pathological tau phosphorylation but strong correlations of phospho-tau markers with other pathological markers as well as cognition provide evidence for reliable disease tracking.

The rise of tau phosphorylation at Braak stage 2 was mirrored by the conformation-specific antibody Alz-50, although as previously discussed non-specific FAC1 binding may be a confounding factor here [14]. The improved MC-1 antibody [37, 81] demonstrated a superior signal associated with diagnosis, Braak staging and cognitive decline. However, MC-1 reactive tau was not elevated significantly until Braak stage 4, at which point both CP13 and AT8 phosphorylation markers were also raised. Tau's ability to adopt folded MC-1-reactive conformation may be increased in situ following phosphorylation at multiple sites as has been observed in vitro [36]. Hence, changes in phosphorylation may indeed be required before conformational changes can occur [51].

Previous studies have shown a robust increase in TOC1 reactivity in $\mathrm{AD}$ compared to control samples [40, 63], but 
Table 5 Correlation of tau and amyloid markers with Braak stage and cognitive scores

\begin{tabular}{|c|c|c|c|c|c|c|}
\hline & \multirow{2}{*}{ Markers } & \multirow{2}{*}{ Braak } & \multicolumn{4}{|c|}{ Cognition } \\
\hline & & & MMSE & CDR Global & CDR Memory & CDR SOB \\
\hline Tau oligomeric & TOC1 & $\begin{array}{l}* * * * \\
r=0.59\end{array}$ & $\begin{array}{c}* * * * ; \\
r=-0.61\end{array}$ & $* * * * ; r=0.63$ & $* * * * ; r=0.62$ & $\begin{array}{c}* * * \\
r=0.57\end{array}$ \\
\hline \multirow{2}{*}{$\begin{array}{c}\text { Tau } \\
\text { conformation }\end{array}$} & MC-1 & $\begin{array}{l}* * * * ; \\
r=0.60\end{array}$ & $\begin{array}{c}* * * * ; \\
r=-0.69\end{array}$ & $* * * * ; r=0.71$ & $* * * * ; r=0.71$ & $\begin{array}{c}* * * ; \\
r=0.62\end{array}$ \\
\hline & Alz-50 & $* ; r=0.32$ & N.S. & N.S. & N.S. & N.S. \\
\hline \multirow{3}{*}{$\begin{array}{c}\text { Tau } \\
\text { phosphorylation }\end{array}$} & CP13 & $\begin{array}{l}* * * * ; \\
r=0.77\end{array}$ & $\begin{array}{c}* * * * ; \\
r=-0.69\end{array}$ & $* * * * ; r=0.69$ & $* * * * ; r=0.71$ & $\begin{array}{l}* * * * ; \\
r=0.67\end{array}$ \\
\hline & PHF-1 & $\begin{array}{l}* * * * \\
r=0.80\end{array}$ & $\begin{array}{c}* * * * \\
r=-0.69\end{array}$ & $* * * * ; r=0.68$ & $* * * * ; r=0.67$ & $\begin{array}{c}* * * \\
r=0.55\end{array}$ \\
\hline & AT8 & $\begin{array}{l}* * * * ; \\
r=0.81\end{array}$ & $\begin{array}{c}* * * * \\
r=-0.69\end{array}$ & $* * * * ; r=0.7$ & $* * * * ; r=0.7$ & $\begin{array}{l}* * * * ; \\
r=0.63\end{array}$ \\
\hline \multirow{3}{*}{$\mathrm{A} \beta$} & $\begin{array}{l}\text { Soluble } \\
\text { (MOAB) }\end{array}$ & $\begin{array}{l}* * * * ; \\
r=0.71\end{array}$ & $\begin{array}{c}* * * * ; \\
r=-0.68\end{array}$ & $* * * * ; r=0.71$ & $* * * * ; r=0.61$ & $* * ; r=0.46$ \\
\hline & $\begin{array}{l}\text { Mono } \\
(6 \mathrm{E} 10)\end{array}$ & $\begin{array}{l}* * * * \\
r=0.57\end{array}$ & $\begin{array}{c}* * * * ; \\
r=-0.57\end{array}$ & $* * * * ; r=0.6$ & $* * * * ; r=0.56$ & $* * ; r=0.47$ \\
\hline & Pyro-glu & $* ; r=0.32$ & N.S. & N.S. & N.S. & N.S. \\
\hline Secretase & BACE1 & N.S. & N.S. & N.S. & N.S. & N.S. \\
\hline APP & $\begin{array}{l}\text { fAPP } \\
(6 \mathrm{E} 10)\end{array}$ & $\begin{array}{c}* * ; \\
r=-0.39\end{array}$ & $\begin{array}{c}* * * ; \\
r=0.52\end{array}$ & $* * ; r=-0.48$ & $* ; r=-0.37$ & $* ; r=-0.41$ \\
\hline
\end{tabular}

Significances $(p)$ and Spearman's r correlations are given for each marker (for details, see previous Tables) with Braak stage as well as with cognitive scores [established via the Mini mental state exam (MMSE) and Global, Memory and Sum of Box (SOB) variants of the clinical dementia rating (CDR)]. The strength of correlation is indicated by the intensity of shading. $* p<0.05, * * p<0.01, * * * p<0.001$ and $* * * * p<0.0001$, N.S. not significant

have not assessed the association of TOC1 with disease progression and cognitive impairment scores. Thus, an important conclusion from our data is that oligomeric tau appears to be a strong predictor of cognitive scores, clinical diagnosis and neuropathological severity. Recent experimental studies have indeed linked low-weight oligomeric tau rather than fibrillary species to e.g. increased neuronal toxicity, impaired axonal transport, inhibition of synaptic plasticity, synaptic loss, mitochondrial impairment and memory deficits [22, 46, 47, 63, 64]. Overall, our data lend direct support to the patho-physiological relevance of nonfilamentous, oligomeric tau. Nevertheless, strong correlations with cognitive decline were also observed for conformational and phospho-tau as previously reported in humans $[25,30]$ and animal models $[43,44,83]$. Our data expand on the suggested disruptive role of monomeric phosphotau [41], and suggest oligomerization caused by pathological modification of monomeric tau to play a key role. Factors causing the formation of oligomeric tau species remain largely undefined, but native tau does not appear to readily self-aggregate under near-physiological conditions [20, 42]. Not surprisingly, several post-translational modifications facilitate tau aggregation, and our current work implies facilitation of oligomerisation via multiple phospho-epitopes, consistent with the extensive co-localization between TOC1 and phospho-ser422 tau, an early pre-tangle phospho-epitope [28], in the EC and cholinergic basal forebrain [63]. Conversely, tau oligomers do not readily co-localise with markers of more mature fibrillary tau species $[63,79]$. Taken together, the coincident appearance 
of phospho-epitopes and oligomerization is supportive of the suggestion that abnormal phosphorylation may facilitate tau oligomerization [35] thus generating pathological tau entities early in the disease process. Nevertheless, future studies are required to better define which phosphoepitopes are directly involved in this process in situ.

With respect to measures of cognitive ability, all markers except Alz-50 provided robust associations. As we focused here on tau species that are soluble in mild detergent, nondenaturing conditions, our findings strongly suggest that soluble tau is sufficient and relevant for cognitive impairment, and adds support to the proposition that soluble pathological species are more relevant to disease progression as opposed to the NFT and plaque inclusions [11]. Correlations obtained here were clearly stronger than previously reported for NT and NFTs in AD and MCI cases [59], despite the limited number of cases and varying origin.

\section{APP processing and soluble A $\beta$ species}

Early stage alterations in $A \beta$ markers were twofold: a diagnosis-specific, progressive decline in fAPP and a corresponding increase in MOAB- 2 reactive $A \beta$ species. The progressive decline of fAPP is in contrast to many other studies, which found either no change $[8,60]$ or an increase $[3,82]$. There are several possible explanations for this inconsistency, but perhaps the most pertinent is the composition of sample groups. None of the previous investigations had quantified APP levels according to individual Braak staging, and here the greatest loss of APP was seen between Braak stage 0 and 2, two stages often pooled into a non-AD control groups. Thus, the early loss of total APP levels may have been overlooked.

The observed reduction in APP may be a consequence of transcriptional downregulation [75], however, the strong negative correlation between total APP and soluble A $\beta$ species suggests increased amyloidogenic APP cleavage. Whilst no change in the expression levels of BACE1 was observed (in contrast to the investigations of others [24, $34]$ ), we cannot rule out the possibility of increased BACE1 activity in $\mathrm{AD}[1,24,72]$.

Regarding $\mathrm{A} \beta$ species, monomeric, pyro-glu modified and total soluble levels were elevated according to diagnosis and Braak stage severity. These forms of $\mathrm{A} \beta$ also robustly correlated with individual Braak stages and both monomeric and soluble levels of $\mathrm{A} \beta$ further correlated, albeit to varying degrees, with measurements of cognition. Our data also suggest that detection of monomeric $A \beta$ via Western blots is not always possible, particularly in non$\mathrm{AD}$ cases, but also in a number of $\mathrm{AD}$ cases. The apparently low levels of soluble monomeric $A \beta$ agree with recent findings which indicate a potential over-estimation of respective $A \beta$ species following aggressive tissue homogenisation via sonification [38]. Genuine soluble, monomeric $A \beta$ species may in some cases be below the detection limit of conventional Western blotting, even in cases with Braak stage 5 pathology [38]. Detection of A $\beta$ may be further complicated, as even common antibodies such as $6 \mathrm{E} 10$ and $4 \mathrm{G} 8$ may only bind sub-species of $A \beta$, dependent on conformation [33]. Regardless of the analytical parameters, monomeric $\mathrm{A} \beta$ was elevated in agreement with both diagnosis and Braak stage, closely matching data from others [67]. Yet, a significant increase occurred only in advanced pathological cases and did not follow a progressive scale, in agreement with previous observations [49].

\section{Oligomeric A $\beta$}

Our data strongly suggest that chemical and physical parameters of standard Western Blot techniques are not suitable for the reliable detection of native $A \beta$ species. Although numerous potential SDS-stable $A \beta$ oligomers were visible following the overexposure of $6 \mathrm{E} 10$ blots, it is far from clear if any of these entities are native to the brain and/or disease relevant. Specifically, this relates to the oligomeric species known as $* 56$, a dodecamer of $A \beta$, which has been identified in several animal models [18] including our own [65], and found to decrease as a function of disease [49]. It has been suggested to be an indicator of a prodromal time window, triggering degenerative cascades before sequestration into increasingly insoluble plaque deposits. Here, such an inverse relationship between disease severity and this oligomeric $A \beta$ species also seemed apparent, declining from early Braak stage cases to high pathology cases. However, the utility of such SDS-stable oligomeric species must be questioned when considering that the presence of SDS, even at low concentrations $(0.2 \%)$ can greatly enhanced the abundance of dimeric [80] trimeric [10] and higher, multimeric $\mathrm{A} \beta$ species $[5,31,32,66]$. Furthermore, and in line with the impact of heat and reducing agents such DTT to modulate amyloidogenic $\beta$-sheet aggregation $[13,45,69]$, we demonstrate that the relative abundance of $* 56$ was strongly reduced and any correlation with disease progression lost in the absence of such treatments. This suggests that some of the previous data may be due to technical artefacts. The observation of highest levels of $* 56$ in Braak stage 0 cases is also somewhat at odds with the hypothesis of $* 56$ being pathologically causative, as one would anticipate lowest levels in healthy adults and thus at least an initial elevation between what is considered a pathology-free status ( $\mathrm{Br} 0)$ and those cases assumed to be at risk of developing $\mathrm{AD}(\mathrm{Br} 2$ and 3).

Contrary to SDS-PAGE resolved oligomers and monomers, dot blot detection of soluble unmodified oligomeric $\mathrm{A} \beta$ allowed consistent detection and demonstrated a robust 
disease-specific increase and a progressive correlation with Braak stages and cognitive decline. Critically, this relationship was completely abolished following heating and induced a similar inverse relationship with disease progression, as observed for $* 56$. Together, our data strongly suggest that artificial modification of $\mathrm{A} \beta$ species has hampered many previous studies, via promotion of soluble $A \beta$ species into oligomeric configurations which may mask epitopes or destroy binding sites. The heat-sensitivity likely explains the reported failure of MOAB-2 immunoreactivity to detect $\mathrm{AD}$ cases from pre-heated basal forebrain lysate following dot blot analysis by others [4] and thus highlights the need to carefully review both sample preparation and subsequent methods for $A \beta$ quantification.

Even though our approach does not allow the detection of particular $\mathrm{A} \beta$ species, MOAB-2 does not cross-react with APP or other metabolites, and it binds a $\mathrm{C}$-terminal epitope with stronger affinity to more toxic $A \beta_{1-42}$ than to $A \beta_{1-40}$, independent of aggregation state [77]). The increase in total soluble levels of $A \beta$ with disease diagnosis is in line with ELISA-based measurements from cortical tissue $[19,50]$. Compared to measurements of insoluble $\mathrm{A} \beta$ [58] and plaque load [6, 59, 62], MOAB-2 reactivity provides much better correlation with cognitive decline (ranging from 0.46 up to 0.71 ) as well as improved correlation with disease progression as established with the biochemical staging of $A \beta$ [67]. Similarly, the immunoreactive levels of soluble $A \beta$ correlated with all tau markers tested (see below). In comparison, strong associations were not observed for pyro-glu $A \beta$ : Although selective for diagnosis, elevations were only apparent between low and high Braak stage cases. Furthermore, pyro-glu $A \beta$ only weakly correlated with individual Braak stages and failed to correlate with any measure of cognition. This is largely at odds with previous reports of disease specificity [52] and toxicity [61], although in agreement with previous work where a correlation was established between levels of pyro-glumodified $\mathrm{A} \beta$ and tau phosphorylation [52].

\section{Early co-localisation of soluble tau and amyloid pathology}

It is fairly well established that $A \beta$ plaques precede the emergence of NFTs in the neocortex, while NFTs are formed earlier in limbic areas [74]. However, our findings clearly indicate that initial emergence of tau pathology coincides with increased soluble $A \beta$ in Brodmann area 21 as early as Braak stages $2-3$. This pathology therefore precedes the emergence of mature NFTs, classically determined at Braak stage 4 in this brain region. Thus, our data suggest a closer overlap for soluble $A \beta$ and tau species in the temporal lobe, contrasting with the spatial separation of the two toxic pathways based on the mature fibrillary forms of these proteins. Thus, at least in Brodmann area 21, the early co-localization of soluble tau and $A \beta$ pathology implies a close spatiotemporal relationship between these two pathologies.

In summary, our findings are supportive of the coincident emergence of disease-relevant, soluble, pre-fibrillar forms of both $A \beta$ and tau during the earliest stages of $A D$. Potentially toxic protein species identified here strongly correlate with Braak staging and cognitive decline. Causal and functional links between $A \beta$ and tau pathways will remain a hotly debated topic, but here we provide evidence that both pre-fibrillar $A \beta$ and tau appear as likely contributors to the pathogenesis of AD. Late-stage insoluble protein aggregates may have very little relevance to the pathogenic mechanisms of disease, and therefore targeting pre-fibrillar tau and/or $A \beta$ species will be a more effective therapeutic strategy for $\mathrm{AD}$.

Acknowledgments We would like to gratefully acknowledge all donors and their families for the tissue provided for this study. Human tissue samples were supplied by the Brains for Dementia Research programme, jointly funded by Alzheimer's Research UK, the Alzheimer's Society and the Medical Research Council, and sourced from the MRC London Neurodegenerative Diseases Brain Bank, the Manchester Brain Bank, the South West Dementia Brain Bank (SWDBB), the Newcastle Brain Tissue Resource and the Oxford Brain Bank. The Newcastle Brain Tissue Resource and Oxford Brain Bank are also supported by the National Institute for Health Research (NIHR) Units. The South West Dementia Brain Bank (SWDBB) receives additional support from BRACE (Bristol Research into Alzheimer's and Care of the Elderly). Alz-50, CP13, MC-1 and PHF-1 antibodies were gifted from Dr. Peter Davies and brain lystates from BACE1 $1^{-1-}$ mice were obtained from Prof Mike Ashford. The work presented here was funded by Alzheimer's Research UK (Grant refs: ARUKPPG2014A-21 and ARUK-NSG2015-1 to BP and DK and NIH/NIA grants NIH/NINDS R01 NS082730 and R01 AG044372 to NK).

Open Access This article is distributed under the terms of the Creative Commons Attribution 4.0 International License (http://creativecommons.org/licenses/by/4.0/), which permits unrestricted use, distribution, and reproduction in any medium, provided you give appropriate credit to the original author(s) and the source, provide a link to the Creative Commons license, and indicate if changes were made.

\section{References}

1. Ahmed RR, Holler CJ, Webb RL, Li F, Beckett TL, Murphy MP (2010) BACE1 and BACE2 enzymatic activities in Alzheimer's disease. J Neurochem 112:1045-1053

2. Alafuzoff I, Arzberger T, Al-Sarraj S, Bodi I, Bogdanovic N, Braak H et al (2008) Staging of neurofibrillary pathology in Alzheimer's disease: a study of the BrainNet Europe Consortium. Brain Pathol 18:484-496

3. Arai H, Lee VM, Messinger ML, Greenberg BD, Lowery DE, Trojanowski JQ (1991) Expression patterns of $\beta$-amyloid precursor protein ( $\beta$-APP) in neural and nonneural human tissues from Alzheimer's disease and control subjects. Ann Neurol 30:686-693 
4. Baker-Nigh A, Vahedi S, Davis EG, Weintraub S, Bigio EH, Klein WL et al (2015) Neuronal amyloid- $\beta$ accumulation within cholinergic basal forebrain in ageing and Alzheimer's disease. Brain 138:1722-1737

5. Barghorn S, Nimmrich V, Striebinger A, Krantz C, Keller P, Janson B et al (2005) Globular amyloid beta-peptide oligomer-a homogenous and stable neuropathological protein in Alzheimer's disease. J Neurochem 95:834-847

6. Berg L, McKeel DW Jr, Miller JP, Storandt M, Rubin EH, Morris JC et al (1998) Clinicopathologic studies in cognitively healthy aging and Alzheimer's disease: relation of histologic markers to dementia severity, age, sex, and apolipoprotein E genotype. Arch Neurol 55:326-335

7. Berger Z, Roder H, Hanna A, Carlson A, Rangachari V, Yue $M$ et al (2007) Accumulation of pathological tau species and memory loss in a conditional model of tauopathy. J Neurosci 27:3650-3662

8. Beyer K, Lao JI, Carrato C, Mate JL, Lopez D, Ferrer I et al (2004) Upregulation of amyloid precursor protein isoforms containing Kunitz protease inhibitor in dementia with Lewy bodies. Brain Res Mol Brain Res 131:131-135

9. Biernat J, Mandelkow EM, Schroter C, Lichtenberg-Kraag B, Steiner B, Berling B et al (1992) The switch of tau protein to an Alzheimer-like state includes the phosphorylation of two serine-proline motifs upstream of the microtubule binding region. EMBO J 11:1593-1597

10. Bitan G, Fradinger EA, Spring SM, Teplow DB (2005) Neurotoxic protein oligomers-what you see is not always what you get. Amyloid 12:88-95

11. Bloom GS (2014) Amyloid-beta and tau: the trigger and bullet in Alzheimer disease pathogenesis. JAMA Neurol 71:505-508

12. Boluda S, Toledo JB, Irwin DJ, Raible KM, Byrne MD, Lee EB et al (2014) A comparison of $A \beta$ amyloid pathology staging systems and correlation with clinical diagnosis. Acta Neuropathol 128:543-550

13. Borzova VA, Markossian KA, Kara DA, Kurganov B (2015) Kinetic regime of dithiothreitol-induced aggregation of bovine serum albumin. Int J BiolMacromol 80:130-138

14. Bowser R, Giambrone A, Davies P (1995) FAC1, a novel gene identified with the monoclonal antibody Alz50, is developmentally regulated in human brain. Dev Neurosci 17:20-37

15. Braak H, Braak E (1995) Staging of Alzheimer's disease-related neurofibrillary changes. Neurobiol Aging 16:271-284

16. Brier MR, Gordon B, Friedrichsen K, McCarthy J, Stern A, Christensen $\mathrm{J}$ et al (2016) Tau and A $\beta$ imaging, CSF measures, and cognition in Alzheimer's disease. Sci Transl Med 8:338ra66

17. Buee L, Bussiere T, Buee-Scherrer V, Delacourte A, Hof PR (2000) Tau protein isoforms, phosphorylation and role in neurodegenerative disorders. Brain Res Brain Res Rev 33:95-130

18. Cheng IH, Scearce-Levie K, Legleiter J, Palop JJ, Gerstein H, Bien-Ly $N$ et al (2007) Accelerating amyloid- $\beta$ fibrillization reduces oligomer levels and functional deficits in Alzheimer disease mouse models. J Biol Chem 282:23818-23828

19. Collins-Praino LE, Francis YI, Griffith EY, Wiegman AF, Urbach J, Lawton A et al. (2014) Soluble amyloid beta levels are elevated in the white matter of Alzheimer's patients, independent of cortical plaque severity. Acta Neuropathol Commun 2:83. doi:10.1186/s40478-014-0083-0

20. Crowther RA, Olesen OF, Smith MJ, Jakes R, Goedert M (1994) Assembly of Alzheimer-like filaments from full-length tau protein. FEBS Lett 337:135-138

21. Cynis H, Scheel E, Saido TC, Schilling S, Demuth HU (2008) Amyloidogenic processing of amyloid precursor protein: evidence of a pivotal role of glutaminyl cyclase in generation of pyroglutamate-modified amyloid-beta. Biochemistry 47:7405-7413
22. Fa M, Puzzo D, Piacentini R, Staniszewski A, Zhang H, Baltrons MA et al (2016) Extracellular Tau oligomers produce an immediate impairment of LTP and memory. Sci Rep 6:19393

23. Ferrer I, Santpere G, Arzberger T, Bell J, Blanco R, Boluda S et al (2007) Brain protein preservation largely depends on the postmortem storage temperature: implications for study of proteins in human neurologic diseases and management of brain banks: a BrainNet Europe Study. J Neuropathol Exp Neurol 66:35-46

24. Fukumoto H, Cheung BS, Hyman BT, Irizarry MC (2002) $\beta$-Secretase protein and activity are increased in the neocortex in Alzheimer disease. Arch Neurol 59:1381-1389

25. Ghoshal N, Garcia-Sierra F, Wuu J, Leurgans S, Bennett DA, Berry RW et al (2002) Tau conformational changes correspond to impairments of episodic memory in mild cognitive impairment and Alzheimer's disease. Exp Neurol 177:475-493

26. Giannakopoulos P, Herrmann FR, Bussiere T, Bouras C, Kovari E, Perl DP et al (2003) Tangle and neuron numbers, but not amyloid load, predicts cognitive status in Alzheimer's disease. Neurology 60:1495-1500

27. Goedert M, Jakes R, Vanmechelen E (1995) Monoclonal antibody AT8 recognises tau protein phosphorylated at both serine 202 and threonine 205. Neurosci Lett 189:167-169

28. Guillozet-Bongaarts AL, Cahill ME, Cryns VL, Reynolds MR, Berry RW, Binder LI (2006) Pseudophosphorylation of tau at serine 422 inhibits caspase cleavage: in vitro evidence and implications for tangle formation in vivo. J Neurochem 97:1005-1014

29. Hardy JA, Higgins GA (1992) Alzheimer's disease: the amyloid cascade hypothesis. Science 256:184-185

30. Haroutunian V, Davies P, Vianna C, Buxbaum JD, Purohit DP (2007) Tau protein abnormalities associated with the progression of alzheimer disease type dementia. Neurobiol Aging 28:1-7

31. Hatami A, 3rd Albay R, Monjazeb S, Milton S, Glabe C (2014) Monoclonal antibodies against $\mathrm{A} \beta 42$ fibrils distinguish multiple aggregation state polymorphisms in vitro and in Alzheimer disease brain. J Biol Chem 289:32131-32143

32. Hepler RW, Grimm KM, Nahas DD, Breese R, Dodson EC, Acton $\mathrm{P}$ et al (2006) Solution state characterization of amyloid $\beta$-derived diffusible ligands. Biochemistry 45:15157-15167

33. Holden P, Horton WA (2009) Crude subcellular fractionation of cultured mammalian cell lines. BMC Res Notes 2:243

34. Holsinger RM, McLean CA, Beyreuther K, Masters CL, Evin $G$ (2002) Increased expression of the amyloid precursor betasecretase in Alzheimer's disease. Ann Neurol 51:783-786

35. Iqbal K, Gong CX, Liu F (2013) Hyperphosphorylation-induced tau oligomers. Front Neurol 4:112

36. Jeganathan S, Hascher A, Chinnathambi S, Biernat J, Mandelkow EM, Mandelkow E (2008) Proline-directed pseudo-phosphorylation at AT8 and PHF1 epitopes induces a compaction of the paperclip folding of Tau and generates a pathological (MC-1) conformation. J BiolChem 283:32066-32076

37. Jicha GA, Bowser R, Kazam IG, Davies P (1997) Alz-50 and $\mathrm{MC}-1$, a new monoclonal antibody raised to paired helical filaments, recognize conformational epitopes on recombinant tau. J Neurosci Res 48:128-132

38. Jimenez S, Navarro V, Moyano J, Sanchez-Mico M, Torres M, Davila JC et al (2014) Disruption of amyloid plaques integrity affects the soluble oligomers content from Alzheimer disease brains. PLoS One 9:e114041

39. Jyoti A, Plano A, Riedel G, Platt B (2010) EEG, activity, and sleep architecture in a transgenic AbetaPPswe/PSEN1A246E Alzheimer's disease mouse. J Alzheimers Dis 22:873-887

40. Kanaan NM, Cox K, Alvarez VE, Stein TD, Poncil S, McKee AC (2016) Characterization of early pathological Tau conformations and phosphorylation in chronic traumatic encephalopathy. J Neuropathol Exp Neurol 75:19-34 
41. Kanaan NM, Morfini GA, LaPointe NE, Pigino GF, Patterson $\mathrm{KR}$, Song $\mathrm{Y}$ et al (2011) Pathogenic forms of tau inhibit kinesindependent axonal transport through a mechanism involving activation of axonal phosphotransferases. J Neurosci 31:9858-9868

42. King ME, Gamblin TC, Kuret J, Binder LI (2000) Differential assembly of human tau isoforms in the presence of arachidonic acid. J Neurochem 74:1749-1757

43. Koss DJ, Robinson L, Drever BD, Plucinska K, Stoppelkamp S, Veselcic P et al (2016) Mutant Tau knock-in mice display frontotemporal dementia relevant behaviour and histopathology. Neurobiol Dis 91:105-123

44. Koss DJ, Robinson L, Mietelska-Porowska A, Gasiorowska A, Sepcic K, Turk T et al (2015) Polymeric alkylpyridinium salts permit intracellular delivery of human Tau in rat hippocampal neurons: requirement of Tau phosphorylation for functional deficits. Cell Mol Life Sci 72:4613-4632

45. Kumar S, Ravi VK, Swaminathan R (2008) How do surfactants and DTT affect the size, dynamics, activity and growth of soluble lysozyme aggregates? Biochem J 415:275-288

46. Lasagna-Reeves CA, Castillo-Carranza DL, Guerrero-Muoz MJ, Jackson GR, Kayed R (2010) Preparation and characterization of neurotoxic tau oligomers. Biochemistry 49:10039-10041

47. Lasagna-Reeves CA, Castillo-Carranza DL, Sengupta U, Clos AL, Jackson GR, Kayed R (2011) Tau oligomers impair memory and induce synaptic and mitochondrial dysfunction in wild-type mice. Mol Neurodegener 6:39. doi:10.1186/1750-1326-6-39

48. Lesne S, Koh MT, Kotilinek L, Kayed R, Glabe CG, Yang A et al (2006) A specific amyloid- $\beta$ protein assembly in the brain impairs memory. Nature 440:352-357

49. Lesne SE, Sherman MA, Grant M, Kuskowski M, Schneider JA, Bennett DA et al (2013) Brain amyloid- $\beta$ oligomers in ageing and Alzheimer's disease. Brain 136:1383-1398

50. Lue LF, Kuo YM, Roher AE, Brachova L, Shen Y, Sue L et al (1999) Soluble amyloid $\beta$ peptide concentration as a predictor of synaptic change in Alzheimer's disease. Am J Pathol 155:853-862

51. Luna-Munoz J, Garcia-Sierra F, Falcon V, Menendez I, ChavezMacias L, Mena R (2005) Regional conformational change involving phosphorylation of tau protein at the Thr231, precedes the structural change detected by Alz-50 antibody in Alzheimer's disease. J Alzheimers Dis 8:29-41

52. Mandler M, Walker L, Santic R, Hanson P, Upadhaya AR, Colloby SJ et al (2014) Pyroglutamylated amyloid- $\beta$ is associated with hyperphosphorylated tau and severity of Alzheimer's disease. Acta Neuropathol 128:67-79

53. Markesbery WR, Schmitt FA, Kryscio RJ, Davis DG, Smith CD, Wekstein DR (2006) Neuropathologic substrate of mild cognitive impairment. Arch Neurol 63:38-46

54. Meakin PJ, Harper AJ, Hamilton DL, Gallagher J, McNeilly AD, Burgess LA et al (2012) Reduction in BACE1 decreases body weight, protects against diet-induced obesity and enhances insulin sensitivity in mice. Biochem J 441:285-296

55. Morris GP, Clark IA, Vissel B (2014) Inconsistencies and controversies surrounding the amyloid hypothesis of Alzheimer's disease. Acta Neuropathol Commun 2:135

56. Morsch R, Simon W, Coleman PD (1999) Neurons may live for decades with neurofibrillary tangles. J Neuropathol Exp Neurol 58:188-197

57. Mufson EJ, Malek-Ahmadi M, Perez SE, Chen K (2016) Braak staging, plaque pathology, and APOE status in elderly persons without cognitive impairment. Neurobiol Aging 37:147-153

58. Naslund J, Haroutunian V, Mohs R, Davis KL, Davies P, Greengard P et al (2000) Correlation between elevated levels of amyloid $\beta$-peptide in the brain and cognitive decline. JAMA 283:1571-1577
59. Nelson PT, Jicha GA, Schmitt FA, Liu H, Davis DG, Mendiondo MS et al (2007) Clinicopathologic correlations in a large Alzheimer disease center autopsy cohort: neuritic plaques and neurofibrillary tangles "do count" when staging disease severity. J Neuropathol Exp Neurol 66:1136-1146

60. Nordstedt C, Gandy SE, Alafuzoff I, Caporaso GL, Iverfeldt K, Grebb JA et al (1991) Alzheimer beta/A4 amyloid precursor protein in human brain: aging-associated increases in holoprotein and in a proteolytic fragment. Proc Natl Acad Sci USA 88:8910-8914

61. Nussbaum JM, Schilling S, Cynis H, Silva A, Swanson E, Wangsanut $\mathrm{T}$ et al (2012) Prion-like behaviour and tau-dependent cytotoxicity of pyroglutamylated amyloid- $\beta$. Nature 485:651-655

62. Parvathy S, Davies P, Haroutunian V, Purohit DP, Davis KL, Mohs RC et al (2001) Correlation between Abetax-40-, Abetax-42-, and Abetax-43-containing amyloid plaques and cognitive decline. Arch Neurol 58:2025-2032

63. Patterson KR, Remmers C, Fu Y, Brooker S, Kanaan NM, Vana L et al (2011) Characterization of prefibrillar Tau oligomers in vitro and in Alzheimer disease. J Biol Chem 286:23063-23076

64. Patterson KR, Ward SM, Combs B, Voss K, Kanaan NM, Morfini $\mathrm{G}$ et al (2011) Heat shock protein 70 prevents both tau aggregation and the inhibitory effects of preexisting tau aggregates on fast axonal transport. Biochemistry 50:10300-10310

65. Plucinska K, Crouch B, Koss D, Robinson L, Siebrecht M, Riedel G et al (2014) Knock-in of human BACE1 cleaves murine APP and reiterates Alzheimer-like phenotypes. J Neurosci 34:10710-10728

66. Pujol-Pina R, Vilaprinyo-Pascual S, Mazzucato R, Arcella A, Vilaseca M, Orozco M et al (2015) SDS-PAGE analysis of $\mathrm{A} \beta$ oligomers is disserving research into Alzheimer s disease: appealing for ESI-IM-MS. Sci Rep 5:14809

67. RijalUpadhaya A, Kosterin I, Kumar S, von Arnim CA, Yamaguchi H, Fandrich M et al (2014) Biochemical stages of amyloidbeta peptide aggregation and accumulation in the human brain and their association with symptomatic and pathologically preclinical Alzheimer's disease. Brain 137:887-903

68. Santacruz K, Lewis J, Spires T, Paulson J, Kotilinek L, Ingelsson $M$ et al (2005) Tau suppression in a neurodegenerative mouse model improves memory function. Science 309:476-481

69. Sasahara K, Yagi H, Naiki H, Goto Y (2007) Heat-induced conversion of $\beta(2)$-microglobulin and hen egg-white lysozyme into amyloid fibrils. J MolBiol 372:981-991

70. Schonheit B, Zarski R, Ohm TG (2004) Spatial and temporal relationships between plaques and tangles in Alzheimer-pathology. Neurobiol Aging 25:697-711

71. Serrano-Pozo A, Qian J, Muzikansky A, Monsell SE, Montine TJ, Frosch MP et al (2016) Thal amyloid stages do not significantly impact the correlation between neuropathological change and cognition in the Alzheimer disease continuum. J Neuropathol Exp Neurol 75:516-526

72. Stockley JH, Ravid R, O'Neill C (2006) Altered $\beta$-secretase enzyme kinetics and levels of both BACE1 and BACE2 in the Alzheimer's disease brain. FEBS Lett 580:6550-6560

73. Thal DR, Rub U, Orantes M, Braak H (2002) Phases of $\mathrm{A} \beta$-deposition in the human brain and its relevance for the development of AD. Neurology 58:1791-1800

74. Thal DR, Rub U, Schultz C, Sassin I, Ghebremedhin E, Del Tredici K et al (2000) Sequence of A $\beta$-protein deposition in the human medial temporal lobe. J Neuropathol Exp Neurol 59:733-748

75. Tharp WG, Lee YH, Greene SM, Vincellete E, Beach TG, Pratley RE (2012) Measurement of altered A $\beta P P$ isoform expression in frontal cortex of patients with Alzheimer's disease by absolute quantification real-time PCR. J Alzheimers Dis 29:449-457 
76. Toledo JB, Zetterberg H, van Harten AC, Glodzik L, MartinezLage P, Bocchio-Chiavetto L et al (2015) Alzheimer's disease cerebrospinal fluid biomarker in cognitively normal subjects. Brain 138:2701-2715

77. Youmans KL, Tai LM, Kanekiyo T, Stine WB Jr, Michon SC, Nwabuisi-Heath E et al. (2012) Intraneuronal $A \beta$ detection in $5 x F A D$ mice by a new $A \beta$-specific antibody. Mol Neurodegener 7:8. doi:10.1186/1750-1326-7-8

78. Villemagne VL, Burnham S, Bourgeat P, Brown B, Ellis KA, Salvado $O$ et al (2013) Amyloid beta deposition, neurodegeneration, and cognitive decline in sporadic Alzheimer's disease: a prospective cohort study. Lancet Neurol 12:357-367

79. Ward SM, Himmelstein DS, Lancia JK, Fu Y, Patterson KR, Binder LI (2013) TOC1: characterization of a selective oligomeric tau antibody. J Alzheimers Dis 37:593-602

80. Watt AD, Perez KA, Rembach A, Sherrat NA, Hung LW, Johanssen $T$ et al (2013) Oligomers, fact or artefact? SDS-PAGE induces dimerization of $\beta$-amyloid in human brain samples. Acta Neuropathol 125:549-564
81. Weaver CL, Espinoza M, Kress Y, Davies P (2000) Conformational change as one of the earliest alterations of tau in Alzheimer's disease. Neurobiol Aging 21:719-727

82. Webster MT, Francis PT, Procter AW, Stratmann GC, Doshi R, Mann DM et al (1994) Postmortem brains reveal similar but not identical amyloid precursor protein-like immunoreactivity in Alzheimer compared with other dementias. Brain Res 644:347-351

83. Xu H, Rosler TW, Carlsson T, de Andrade A, Bruch J, Hollerhage $\mathrm{M}$ et al (2014) Memory deficits correlate with tau and spine pathology in P301S MAPT transgenic mice. Neuropathol Appl Neurobiol 40:833-843

84. Zhou XW, Li X, Bjorkdahl C, Sjogren MJ, Alafuzoff I, Soininen $\mathrm{H}$ et al (2006) Assessments of the accumulation severities of amyloid $\beta$-protein and hyperphosphorylated tau in the medial temporal cortex of control and Alzheimer's brains. Neurobiol Dis 22:657-668 